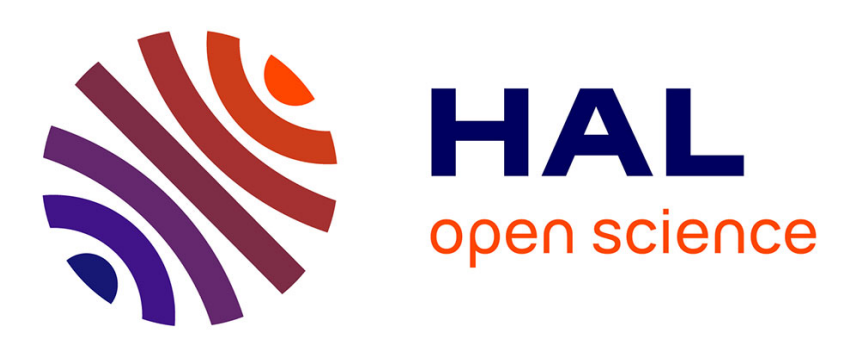

\title{
Fluid Substitution and Shear Weakening in Clay-Bearing Sandstone at Seismic Frequencies
}

Hanjun Yin, Jan V. M. Borgomano, Shangxu Wang, Mathilde Tiennot, Jerome Fortin, Yves Gueguen

\section{- To cite this version:}

Hanjun Yin, Jan V. M. Borgomano, Shangxu Wang, Mathilde Tiennot, Jerome Fortin, et al.. Fluid Substitution and Shear Weakening in Clay-Bearing Sandstone at Seismic Frequencies. Journal of Geophysical Research: Solid Earth, 2019, 124 (2), pp.1254-1272. 10.1029/2018JB016241 . hal02329805

\section{HAL Id: hal-02329805 https://hal.science/hal-02329805}

Submitted on 30 Oct 2019

HAL is a multi-disciplinary open access archive for the deposit and dissemination of scientific research documents, whether they are published or not. The documents may come from teaching and research institutions in France or abroad, or from public or private research centers.
L'archive ouverte pluridisciplinaire HAL, est destinée au dépôt et à la diffusion de documents scientifiques de niveau recherche, publiés ou non, émanant des établissements d'enseignement et de recherche français ou étrangers, des laboratoires publics ou privés. 


\section{RESEARCH ARTICLE 10.1029/2018JB016241}

\section{Special Section:}

Physical Properties of Rocks, Friction and Fracturing: The Walsh Volume

Key Points:

- Elastic moduli dispersion and attenuation on a Thüringen sandstone are measured using forced oscillation and ultrasonic transmission method

- The measured dispersion and attenuation for the water-saturated Thüringen sandstone correspond to the drained/undrained transition

- Clear shear weakening violates Gassmann's prediction and is interpreted as the reduction of surface energy due to chemical interaction

Supporting Information:

- Supporting Information S1

- Table S1

- Table S2

- Table S3

- Table S4

- Table S5

Correspondence to:

H. Yin,

yin@geologie.ens.fr

Citation:

Yin, H., Borgomano, J. V. M., Wang, S., Tiennot, M., Fortin, J., \& Guéguen, Y. (2019). Fluid substitution and shear weakening in clay-bearing sandstone at seismic frequencies. Journal of Geophysical Research: Solid Earth, 124, 1254-1272. https://doi.org/10.1029/ 2018JB016241

Received 16 JUN 2018 Accepted 12 JAN 2019 Accepted article online 16 JAN 2019 Published online 4 FEB 2019

\section{Fluid Substitution and Shear Weakening in Clay-Bearing Sandstone at Seismic Frequencies}

\author{
Hanjun Yin ${ }^{1,2}$ (D) Jan V. M. Borgomano' ${ }^{1}$, Shangxu Wang ${ }^{2}$ (D), Mathilde Tiennot ${ }^{3}$, \\ Jérôme Fortin ${ }^{1}$, and Yves Guéguen ${ }^{1}$ \\ ${ }^{1}$ Laboratoire de Géologie, Ecole normale supérieure/CNRS UMR8538, PSL Research University, Paris, France, ${ }^{2}$ State Key \\ Laboratory of Petroleum Resources and Prospecting, China University of Petroleum-Beijing, Beijing, China, ${ }^{3}$ Laboratoire \\ Sciences et Ingénierie de la Matière Molle, ESPCI Paris, PSL University, Sorbonne Université, CNRS, Paris, France
}

Abstract Using the forced oscillation method and the ultrasonic transmission method, we measure the elastic moduli of a clay-bearing Thüringen sandstone under dry and water-saturated conditions in a broad frequency band at $\left[0.004-10,10^{6}\right] \mathrm{Hz}$ for different differential pressures up to $30 \mathrm{MPa}$. Under water-saturated condition, clear dispersion and attenuation for Young's modulus, Poisson's ratio, and Bulk modulus are observed at seismic frequencies, except for shear modulus. The measured dispersion and attenuation are mainly attributed to the drained/undrained transition, which considers the experimentally undrained boundary condition. Gassmann's predictions are consistent with the measured undrained bulk moduli but not with the shear moduli. Clear shear weakening is observed, and this water-softening effect is stronger at seismic frequencies than at ultrasonic frequencies where stiffening effect related to squirt flow may mask real shear weakening. The reduction in surface free energy due to chemical interaction between pore fluid and rock frame, which is not taken into account by Gassmann's theory, is the main reason for the departure from Gassmann's predictions, especially for this rock containing a large number of clay minerals.

\section{Introduction}

Seismic surveys and well logging are two primary methods to explore and characterize hydrocarbon reservoirs (Ellis \& Singer, 2007; Sheriff \& Geldart, 1995) or aquifers (Adelinet et al., 2018). In order to improve our understanding of fluid distribution and pressure variation in reservoirs during oil production, time-lapse seismic monitoring has been utilized (Kasahara \& Hasada, 2016; Lumley, 2001). A key to reducing risk and uncertainty for these procedures has always been effectively and quantitatively relating the physical properties of reservoir rocks to their geophysical signatures, which is known as rock physics analysis (Avseth et al., 2010; Mavko et al., 2009).

The goal of rock physics is to develop models that enable us to understand the interaction of lithology and fluid as a function of rock type, fluid content, and reservoir quality. Several theoretical models currently exist for the description of the poroelastic or viscoelastic behavior of rocks. However, Gassmann's theory is the most widely used rock physics theory because of its important role in fluid substitution (Smith et al., 2003). Gassmann's equations are written as (Gassmann, 1951)

$$
\begin{aligned}
& K_{u}=K_{d}+\frac{\left(1-\frac{K_{d}}{K_{m}}\right)^{2}}{\frac{\phi}{K_{f}}+\frac{1-\phi}{K_{m}}-\frac{K_{d}}{K_{m}^{2}}}, \\
& G_{u}=G_{d}
\end{aligned}
$$

where $K_{d}, K_{u}, K_{f}$, and $K_{m}$ are the dry, undrained, fluid, and mineral matrix bulk moduli, respectively. $G_{d}$ and $G_{u}$ are the dry and undrained shear moduli, respectively. The $\phi$ is the rock's porosity.

The derivation and application of Gassmann's equations assume that the rock is isotropic and homogeneous, that the frequency is sufficiently low where fluid pressure is equalized in the undrained system (no pore fluid movement across rock boundaries), and that there is no chemical interaction between rock frame and pore fluid (Berryman, 1999; Gassmann, 1951). Comparisons between experimental results at ultrasonic frequencies and theoretical predictions by Gassmann's theory for compressional and shear velocities are usually performed (Assefa et al., 2003; Bhuiyan \& Holt, 2016; Domenico, 1977; Han et al., 1986; Japsen et al., 
2002; Wang et al., 1991). Most research observed that Gassmann's predicted saturated compressional velocities underestimated the measured ultrasonic velocities (Vo-Thanh, 1995; Wang, 2000). More recently, Regnet et al. (2015) used the discrepancy between Gassmann's predictions and ultrasonic measurements to identify samples with microcracks. Indeed, Gassmann's theory assumes pore pressure equilibration through all the pores at the representative element volume scale, and the measurements at high ultrasonic frequencies may not meet this assumption, especially for rocks containing microcracks (Adelinet et al., 2011). Saturated rocks are known to be dispersive (Müller et al., 2010). Thus, when comparing Gassmann's predictions with laboratory ultrasonic measurements, the effect of frequency on elastic moduli needs to be considered. That is why several laboratory facilities with a low-frequency measurement range have been developed during the past 40 years (Best et al., 2007; Fortin et al., 2014; Jackson, 2000; Jackson et al., 2011; Jackson \& Paterson, 1993; Madonna \& Tisato, 2013; McCarthy et al., 2011; Mikhaltsevitch et al., 2014; Murphy, 1985; Nakagawa et al., 2013; Peselnick \& Liu, 1987; Saltiel et al., 2017; Spencer, 1981; Subramaniyan et al., 2014; Szewczyk et al., 2016; Tisato \& Madonna, 2012; Wang et al., 2012; Yin et al., 2017). Murphy (1985) conducted laboratory measurements on granites using the resonant bar method at sonic frequency supplemented with the ultrasonic method and found that Gassmann's predictions worked better for low sonic frequency measurements. Batzle et al. (2006) discussed the influence of fluid viscosity on the elastic moduli of sandstones based on forced oscillation measurements in the seismic frequency range below $100 \mathrm{~Hz}$. Their water-saturated results could be generally explained by Gassmann's equations, but they also pointed out that the nature of the fluid might influence the shear modulus by varying the fluid-solid interaction. Pimienta et al. (2015a, 2015b), Pimienta, Borgomano, et al. (2016), and Pimienta, Fortin, and Guéguen (2016) conducted a series of low-frequency measurements to study the frequency dependence for the bulk modulus, Young's modulus, and Poisson' ratio of fully saturated Fontainebleau sandstones. They found two transitions: (i) a first transition called the drained/undrained transition, which was related to rock properties and the experimental boundary conditions, and (ii) a second transition due to squirt flow. The drained/undrained transition of bulk modulus dispersion and related attenuation could be generally modeled by a one-dimensional (1-D) poroelastic model considering the existence of dead volumes (Pimienta, Borgomano, et al., 2016). This model was reduced to Gassmann's theory under zero dead volume condition.

Furthermore, various ultrasonic results have shown that shear modulus does not always remain constant after fluid saturation as predicted by Gassmann's theory (Baechle et al., 2009; Green \& Wang, 1994; Vialle $\&$ Vanorio, 2011). The variation of shear modulus for a fluid-saturated rock, either a net increase (strengthening) or a net decrease (weakening), has been attributed to the combined effect of several factors, such as fluid-solid interaction, clay degradation or expansion, and viscous coupling (Cadoret, 1993; Diethart-Jauk \& Gegenhuber, 2018; Khazanehdari \& Sothcott, 2003; Tutuncu \& Sharma, 1992). Data about the fluid saturation effect on shear modulus are comparatively rare at seismic frequencies. Adam et al. (2006) explored the sensitivity of shear modulus to fluids by measuring nine different carbonate samples under dry condition and butane and brine saturation in the seismic frequency range. They found clear shear weakening at seismic frequencies for some carbonates and general consistency between dry shear modulus and saturated shear modulus at ultrasonic frequencies. Mikhaltsevitch et al. (2016a) discussed the influence of fluid type on the elastic moduli of a limestone under n-decane and water saturation. Their data displayed that the measured bulk modulus was consistent with Gassmann's theory. However, the shear modulus decreased only under water saturation and remained unchanged under n-decane saturation. That indicated that water might play an important role in shear weakening.

In general, the reason for the failure of Gassmann's predictions is the violation of Gassmann's assumptions including pore pressure equilibrium at the representative element volume scale and no chemical interaction between pore fluid and rock frame. The low-frequency facilities are able to evaluate the effect of frequency on elastic moduli. Furthermore, they can operate at a very low frequency range, which may lead to closely matching Gassmann's assumption of pore pressure equilibration for a given rock with respect to the ultrasonic transmission method.

To better check Gassmann's theory and especially the assumption of fluid insensitive shear modulus, that is, $G_{u}=G_{d}$, a clay-bearing Thüringen sandstone is tested over a broad frequency range of $\left[0.004-10,10^{6}\right] \mathrm{Hz}$ 
under different differential pressures. The frequency effect on elastic moduli of the fluid-saturated rock, especially on shear modulus, is discussed.

\section{Measurement System}

The system we used is a new triaxial cell equipped with a maneuverable axial piston at École Normale Supérieure of Paris (Borgomano, 2018). This system is similar to the one used by Adelinet et al. (2010), David et al. (2013), Pimienta et al. (2015a, 2015b), and Pimienta, Fortin, and Guéguen (2016). Its schematic diagram is shown in Figure 1. It combines the forced oscillation method and the ultrasonic transmission method and allows for measurements under confining pressures up to $300 \mathrm{MPa}$ and deviatoric stress up to 1,000 MPa (Fortin et al., 2007; Pimienta et al., 2017). With an outer rubber jacket around sample's lateral surface, contamination with confining oil is avoided and pore pressure can be independently controlled by two pore pressure pumps connecting with the upstream and downstream pipelines.

The forced oscillation method includes two different oscillation modes: hydrostatic oscillation and axial oscillation. Regardless of which mode is utilized, the method measures stress oscillation and the resulting sample's strain oscillation to deduce the dynamic elastic moduli and corresponding attenuation of the rock sample. Sample's strains are obtained from four pairs of axial and radial strain gauges (FCB-6-350-11, Tokyo Sokki TML) glued equidistantly around the sample's surface at midheight. The axial and radial strain gauges of 6-mm length are parallel and normal to the sample's central axis, respectively. To measure the axial stress applied to the sample, four axial strain gauges are installed on the aluminum endplate on which the sample is placed. It should be emphasized that subsequent signal analysis uses the mean signal of the four strain gauges in one direction in order to compensate for the possible effect of load disalignment and rock heterogeneity (Takei et al., 2011). Thus, the exerted stress for each mode is obtained either by recording the confining stress from the pressure sensor inside the cell for hydrostatic oscillation or by deducing the axial stress from the deformation of the aluminum endplate for axial oscillation. Furthermore, the magnitude of the stress oscillation is calibrated so that the strain is in the order of $10^{-6}$ for each mode. Therefore, the analysis of rock deformation can be accomplished by using linear elastic mechanics (Winkler et al., 1979). If a rock is assumed homogeneous and isotropic, its stiffness tensor is characterized by only two independent elastic moduli, which can be easily calculated based on the exerted stress and obtained strain.

Two oscillation modes depend on the position of the axial piston and the type of vibration exciter. When the axial piston is disengaged, one mode, hydrostatic oscillation, is applied at frequencies from $0.004 \mathrm{up}$ to $1.1 \mathrm{~Hz}$ by the confining pump, which exerts a controlled sinusoidal confining stress on the whole sample to acquire the bulk modulus $K_{\text {hydro }}$ and corresponding attenuation $Q_{K_{\text {hydro }}}^{-1}$ (Pimienta et al., 2015a),

$$
K_{\text {hydro }}=\frac{\Delta P_{c}}{\varepsilon_{\mathrm{vol}}} \text { and } Q_{K_{\text {hydro }}}^{-1}=\tan \left(\varphi_{\Delta P_{c}}-\varphi_{\varepsilon_{\mathrm{vol}}}\right)
$$

where $\Delta P_{c}$ is the oscillating confining stress around the mean confining stress. $\varepsilon_{\mathrm{vol}} \approx \varepsilon_{\text {axial }}+2 \varepsilon_{\text {radial }}$ is the volumetric strain, which approximates to the sum of the sample's axial strain $\varepsilon_{\text {axial }}$ and twice the sample's radial strain $\varepsilon_{\text {radial }}$ under pure hydrostatic oscillation. $\varphi_{\Delta P_{c}}$ and $\varphi_{\varepsilon_{\mathrm{vol}}}$ are the phase angles of the oscillating confining stress and volumetric strain, respectively.

By comparison, when the axial piston is engaged, the other mode, axial oscillation, is implemented by the piezoelectric oscillator (P-056.20P, PI Ceramic $\mathrm{GmbH}$ ) at frequencies from 0.1 to $10 \mathrm{~Hz}$. The column composed of the sample and the aluminum endplate is equally loaded by the axial stress $\sigma_{\text {axial }}$ along the column's central axis, so the stress is assumed uniform through the sample and the aluminum endplate, and thus, the Young's modulus $E$, Poisson's ratio $\nu$, and corresponding attenuations $Q_{E}^{-1}$ and $Q_{\nu}^{-1}$ can be calculated using (Batzle et al., 2006; Madonna \& Tisato, 2013; Pimienta et al., 2015b; Pimienta, Fortin, \& Guéguen, 2016),

$$
\begin{aligned}
& E=\frac{\sigma_{\text {sample }}}{\varepsilon_{\text {axial }}}=\frac{\sigma_{a l}}{\varepsilon_{\text {axial }}}=\frac{E_{a l} \varepsilon_{a l}}{\varepsilon_{\text {axial }}} \text { and } \quad \nu=-\frac{\varepsilon_{\text {radial }}}{\varepsilon_{\text {axial }}} \\
& Q_{E}^{-1}=\tan \left(\varphi_{\varepsilon_{a l}}-\varphi_{\varepsilon_{\text {axial }}}\right) \quad \text { and } \quad Q_{\nu}^{-1}=\tan \left(\varphi_{\varepsilon_{\text {radial }}}-\varphi_{\varepsilon_{\text {axial }}}\right),
\end{aligned}
$$

where the axial stress loaded on the sample $\sigma_{\text {sample }}$ is equal to the axial stress on the aluminum endplate $\sigma_{a l}=E_{a l} \varepsilon_{a l}$, which can be calculated from the acquired strain $\varepsilon_{a l}$ of the aluminum endplate with its known Young's modulus $E_{a l} . \varphi_{\varepsilon_{a l}}$ is the phase angle of the axial strain of the aluminum endplate. $\varphi_{\varepsilon_{\text {axial }}}$ and $\varphi_{\varepsilon_{\text {radial }}}$ are 


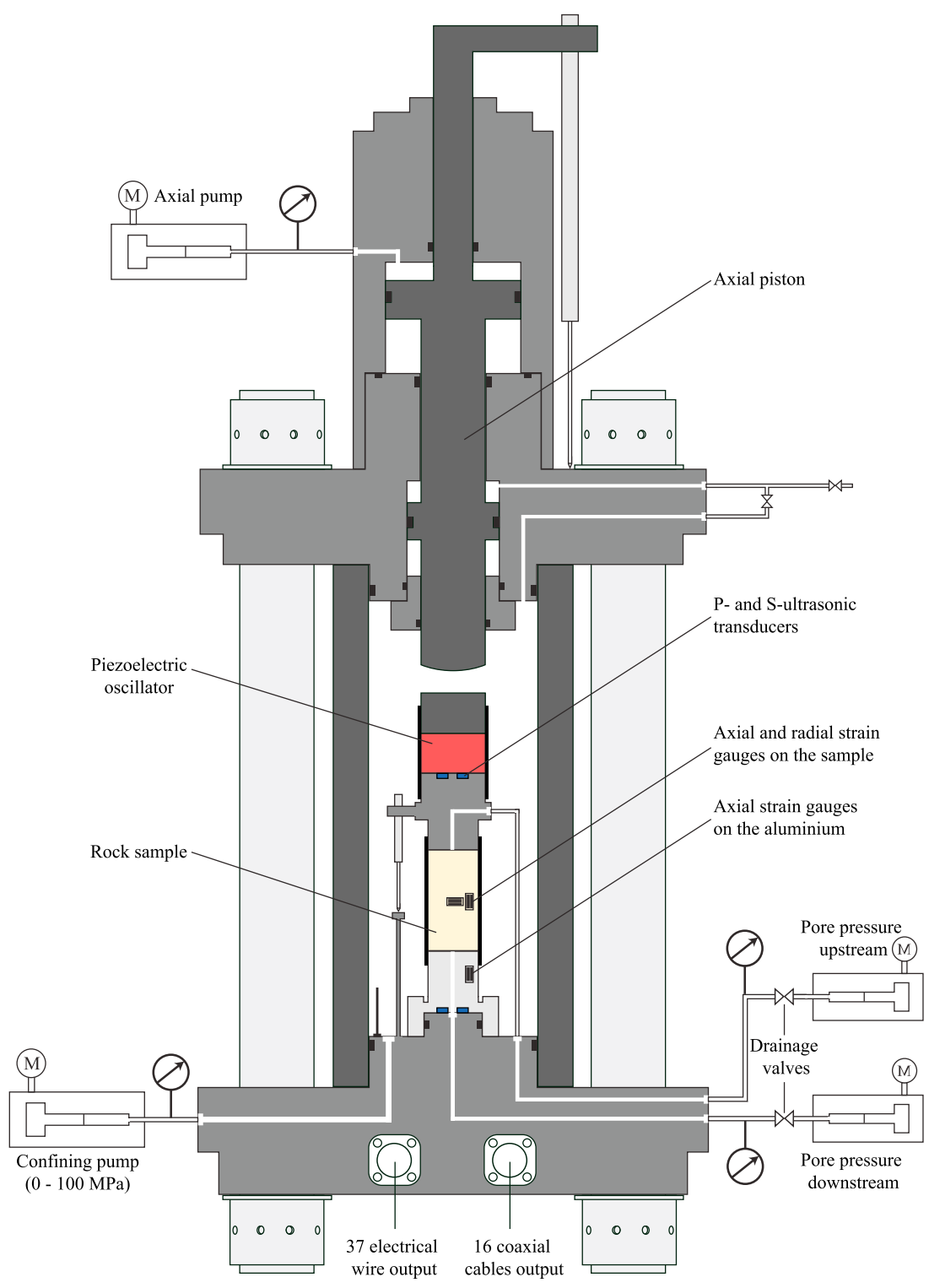

Figure 1. Schematic diagram of the measurement system (Borgomano, 2018).

the phase angles of the axial and radial strain of the sample, respectively. The other elastic properties can be deduced from the combination of the obtained stress and strain (Batzle et al., 2006; Birch, 1961; Borgomano et al., 2017),

$$
\begin{aligned}
& K=\frac{\sigma_{a l}}{3\left(\varepsilon_{\text {axial }}+2 \varepsilon_{\text {radial }}\right)} \quad \text { and } G=\frac{\sigma_{a l}}{2\left(\varepsilon_{\text {axial }}-\varepsilon_{\text {radial }}\right)} \\
& Q_{K}^{-1}=\tan \left(\varphi_{\varepsilon_{a l}}-\varphi_{\varepsilon_{\text {axial }}+2 \varepsilon_{\text {radial }}}\right) \text { and } Q_{G}^{-1}=\tan \left(\varphi_{\varepsilon_{a l}}-\varphi_{\varepsilon_{\text {axial }}-\varepsilon_{\text {radial }}}\right)
\end{aligned}
$$

where $K$ and $Q_{K}^{-1}$ are the bulk modulus and corresponding attenuation, respectively. $G$ and $Q_{G}^{-1}$ are the shear modulus and corresponding attenuation, respectively. $\varphi_{\varepsilon_{\text {axial }}+2 \varepsilon_{\text {radial }}}$ and $\varphi_{\varepsilon_{\text {axial }}-\varepsilon_{\text {radial }}}$ are the phase angles of the combined strains $\varepsilon_{\text {axial }}+2 \varepsilon_{\text {radial }}$ and $\varepsilon_{\text {axial }}-\varepsilon_{\text {radial }}$, respectively. A typical processing method, fast Fourier transform, is used to derive the amplitudes and phase angles of the recorded or combined signals for each frequency (Batzle et al., 2006; Madonna \& Tisato, 2013; Mikhaltsevitch et al., 2014).

In addition, fluid pressure $P_{f}^{*}$ is also recorded by pressure sensors in the fluid pipelines near both ends of the sample during oscillation. Due to the existence of a dead volume (the limited volume of fluid pipelines 
connected to the sample) when the valves of the pipelines are closed, fluid pressure built up outside the sample may adjust and fluid exchange will happen at sample's boundaries. Thus, the sample is in an experimentally undrained condition but not in a purely undrained condition, at which no fluid moves in or out of the sample. A pseudo-Skempton coefficient $B^{*}$ for hydrostatic oscillation and a pseudoconsolidation coefficient $\gamma^{*}$ for axial oscillation are defined to be the ratios of the induced fluid pressure measured in the dead volume to the change in applied stress (Pimienta et al., 2015a, 2015b),

$$
\frac{\Delta P_{f}^{*}}{\sigma_{i i} / 3}=\left\{\begin{array}{l}
B^{*}=\frac{\Delta P_{f}^{*}}{\Delta P_{c}} \quad \text { for hydrostatic oscillation } \\
3 \gamma^{*}=\frac{\Delta P_{f}^{*}}{\sigma_{\text {axial }} / 3} \text { for axial oscillation }
\end{array}\right.
$$

where $\Delta P_{f}^{*}$ is the oscillating fluid pressure around the mean fluid pressure. The equivalent volumetric stress $\sigma_{i i} / 3$ can be expressed as $\Delta P_{c}$ for hydrostatic oscillation and $\sigma_{\text {axial }} / 3$ for axial oscillation (Borgomano et al., 2017). Normally, $B^{*}=3 \gamma^{*}$.

The ultrasonic transmission method is used to measure compressional velocity $V_{p}$ and shear velocity $V_{s}$ of rock samples at high frequencies. The central frequencies for the compressional and shear wave ultrasonic transducers are 1 and $0.5 \mathrm{MHz}$, respectively. The errors for the measured $V_{p}$ and $V_{s}$ are less than $2 \%$ and 5\%, respectively (Fortin et al., 2007), originating from the uncertainties in sample's length and the determination of the first arrival time of compressional and shear waves. The bulk modulus $K_{\text {high }}$, shear modulus $G_{\text {high }}$, Young's modulus $E_{\text {high }}$, and Poisson's ratio $\nu_{\text {high }}$ can be calculated by

$$
\begin{aligned}
& K_{\text {high }}=\rho\left(V_{P}^{2}-\frac{4}{3} V_{S}^{2}\right) \text { and } \mathrm{G}_{\mathrm{high}}=\rho V_{S}^{2} \\
& E_{\mathrm{high}}=\frac{9 K_{\mathrm{high}} G_{\mathrm{high}}}{3 K_{\mathrm{high}}+G_{\mathrm{high}}} \text { and } \nu_{\mathrm{high}}=\frac{3 K_{\mathrm{high}}-2 G_{\mathrm{high}}}{2\left(3 K_{\mathrm{high}}+G_{\mathrm{high}}\right)},
\end{aligned}
$$

where $\rho=\rho_{\mathrm{dry}}+\phi \rho_{f}$ is the density of the fluid-saturated sample. $\rho_{\mathrm{dry}}$ and $\rho_{f}$ are the densities of the dry sample and the saturating fluid, respectively.

Overall, by combining the forced oscillation method and the ultrasonic transmission method, the measurement system at ENS is competent to measure the dispersion and attenuation of rocks saturated with various pore fluids over a broad frequency range.

\section{Sample Description}

A clay-bearing sandstone from the Thüringen Basin in Germany is investigated. The variation of rock's physical properties due to water vapor sorption under environmental exposure conditions has been studied previously (Tiennot et al., 2017). Even though velocity measurements reveal that the rock is transversally isotropic due to natural orientation of clay, the largest difference of compressional velocities in different directions is less than 3\%; thus, the rock will be considered homogeneous and isotropic in this research (Tiennot et al., 2017).

The cylindrical sample is $8.04 \mathrm{~cm}$ in length and $4 \mathrm{~cm}$ in diameter. The flat and smooth ends of the sample are rectified to be parallel by polishing with a tolerance of $1 \mu \mathrm{m}$. Connected porosity derived from mercury injection test is 13\%. The thin section in Figure 2 shows that our Thüringen sandstone is mainly composed of quartz with subordinate feldspars. Furthermore, feldspars are largely degraded due to weathering (Parsons, 2012; Van Der Plas, 2011). This is further confirmed by clay mineral identification with the Xray diffraction analysis, detecting muscovite, illite, and kaolinite, especially mixed-layered chlorite-smectite and illite-smectite minerals. The mineral composition obtained from X-ray diffraction is shown in Table 1. The observation of the thin section also makes it possible to quantify all the clay phases lining the grains, representing about $20 \%$ of the rock in Figure 2.

Detailed mineral topographical and elemental information is revealed by the field emission scanning electron microscopy analysis. A clusters of regularly interstratified chlorite-smectite platelets are observed in the center of Figure 3a. These well-developed phases form webby coatings, which are widely distributed 


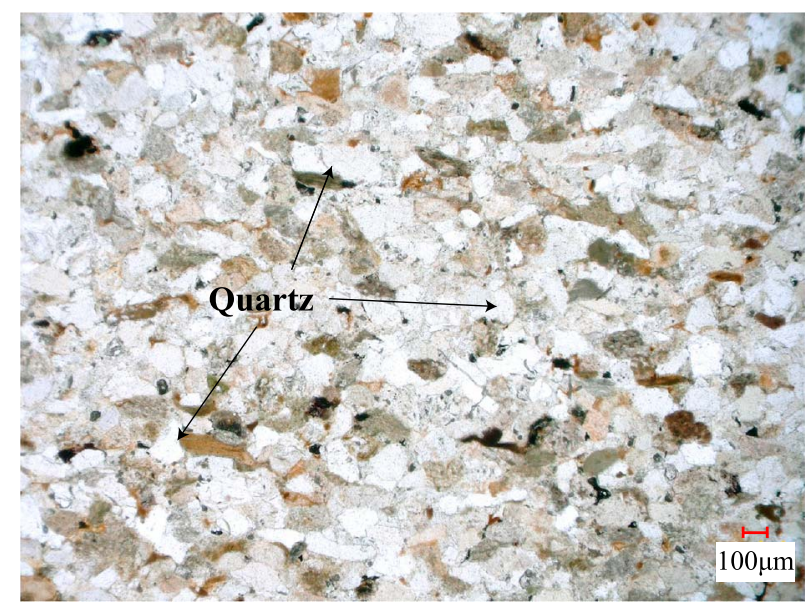

Figure 2. Thin section of the Thüringen sandstone in natural light (from Tiennot, 2017). partly surrounding the rock matrix. Illite is in the form of very thin rods shown in Figure 3b. The netted webs formed by illite are covering the surface of sand grains and bridging between the grains shown in Figure $3 \mathrm{~b}$.

\section{Measurement Protocol}

In order to investigate the effect of fluid on the elastic moduli over a broad frequency range, the Thüringen sandstone is measured sequentially under dry and water-saturated conditions at different differential pressures. The physical properties of the two pore fluids are shown in Table 2 .

Measurements on the dry sample are first conducted. Once the prepared sample is mounted in the cell, an initial load/unload cycle is performed. The sample is loaded at a constant stress rate of $0.2 \mathrm{MPa} / \mathrm{min}$ to a fixed confining pressure of $P_{c}=30 \mathrm{MPa}$, held stable for $1 \mathrm{hr}$, and followed by an unloading at the same stress rate to $P_{c}=5 \mathrm{MPa}$. After this cycle, ultrasonic transmission measurements are conducted to obtain the high-frequency velocities. Then, hydrostatic oscillation at frequency $f_{\text {hydro }}=[0.004,1.1] \mathrm{Hz}$ and axial oscillation at frequency $f_{\text {axial }}=[0.1,10] \mathrm{Hz}$ are subsequently carried out. It should be noted that under axial oscillation, a differential stress of $0.5 \mathrm{MPa}$ is exerted by the axial piston to ensure a good contact between the piezoelectric oscillator and the sample. The ultrasonic and forced oscillation measurements are carried out for each confining pressure from 5 up to $30 \mathrm{MPa}$ with steps of $5 \mathrm{MPa}$.

Then the sample is measured under water saturation. The frequencies and differential pressures of the ultrasonic and forced oscillation measurements are identical to that for the dry condition. An additional permeability measurement based on Darcy's law is performed prior to each set of ultrasonic or forced oscillation measurements. Since the pressure difference between the downstream and upstream pressures for each permeability measurement is $0.2 \mathrm{MPa}$, pore pressure tends to be uniform throughout the connected pores in the sample after the permeability tests involving fluid flow through the whole sample. In order to guarantee pore pressure equilibration, the downstream and upstream pressures will set to the same value and remain unchanged for $30 \mathrm{~min}$. In general, monitoring permeability after changing confining pressure not only reduces uneven pore pressure distribution in the porous sample but also enables us to calculate the characteristic frequency of the drained/undrained transition (Pimienta, Borgomano, et al., 2016).

In the case of fluid-saturated samples, dead volume should be considered (Pimienta, Borgomano, et al., 2016). Indeed, elastic moduli of the samples will depend on dead volume in the drained/undrained transition. Thus, the valves, which control dead volume, are kept open for permeability measurements and confining pressure regulations and are closed during oscillation measurements. A constant large dead volume $V_{\text {dead }}$ around $\sim 50 \mathrm{ml}$ is chosen to approach the drained state for the water-saturated sample. In other words, the fluid mass in the enclosed area composed of the pore space and the dead volume keeps constant for all the forced oscillation measurements.

\section{Results}

\subsection{Ultrasonic Results and Permeability}

Under dry and water-saturated conditions, the nonlinear variation of ultrasonic compressional velocity $V_{P}$ with differential pressure $P_{\text {dif }}=P_{c}-P_{f}$ is shown in Figure 4a. $V_{P}$ increases with differential pressure, but the slope of velocity-pressure curve decreases with differential pressure. Above $P_{\text {dif }}=15 \mathrm{MPa}, V_{P}$ gradually exhibits a linear relation with differential pressure. The variation of ultrasonic shear velocity $V_{S}$ as a function of differential pressure is similar to that of $V_{P}$. However, the values of $V_{P}$ and $V_{S}$ under dry and watersaturated conditions are different. After fluid substitution to water saturation, $V_{P}$ increases almost by the same amount for each differential 

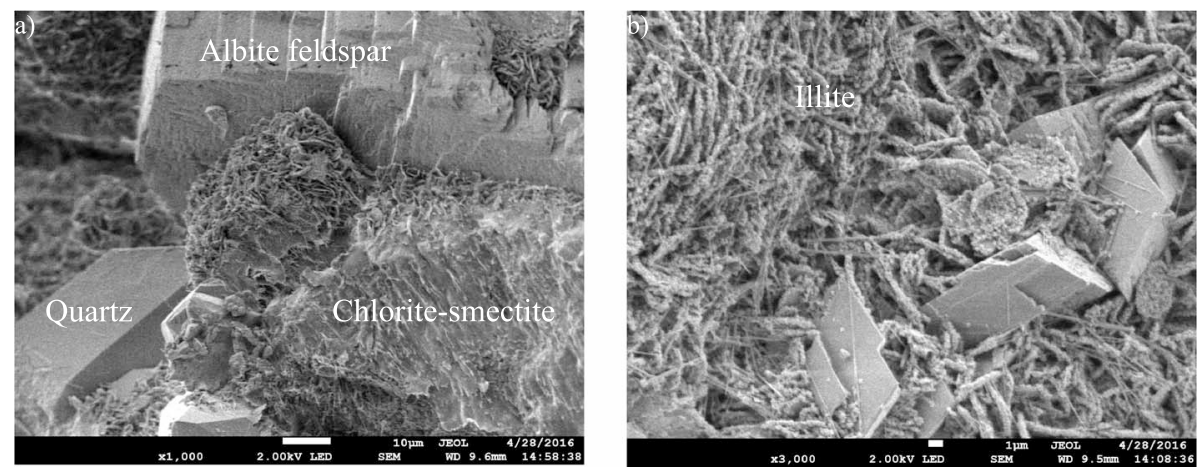

Figure 3. Field emission scanning electron microscopy images of the Thüringen sandstone showing the main grains and clusters of clays (from Tiennot, 2017). (a) A large number of flakes in the lower right are chlorite-smectite. The large prismatic mineral at the top of the photo is albite feldspar. The blocky mineral in the lower left is quartz. (b) Elongated rods of the pore-lining illite covered by oxide particles.

pressure, while on the contrary, $V_{S}$ decreases by about $100 \mathrm{~m} / \mathrm{s}$ with respect to the value for the dry sample at the same differential pressure.

Figure $4 \mathrm{~b}$ shows the measured permeability for the Thüringen sample under water saturation. The initial permeability $\kappa$ is $0.04 \times 10^{-15} \mathrm{~m}^{2}$ and decreases slightly with increasing differential pressure.

\subsection{Hydrostatic Oscillation Results}

The bulk modulus and corresponding attenuation under hydrostatic oscillations are shown in Figure 5. The error bars for the bulk modulus are computed based on the uncertainty analysis procedure elaborated by Borgomano et al. (2017). The bulk modulus derived from the ultrasonic velocities based on equation (6) is also shown in Figure 5 for comparison.

For dry measurements at each differential pressure (Figures 5a and 5b), the bulk modulus measured under hydrostatic oscillation exhibits almost no frequency dependence and is generally consistent with the value derived from the ultrasonic velocities. The corresponding attenuation is below 0.03 . The effect of differential pressure on bulk modulus is clear. The bulk modulus of the dry sample increases from $\sim 9 \mathrm{GPa}$ at the lowest differential pressure $P_{\text {dif }}=5 \mathrm{MPa}$ to $\sim 15 \mathrm{GPa}$ at the highest differential pressure $P_{\text {dif }}=30 \mathrm{MPa}$ due to the closure of preexisting cracks.

Under water-saturated condition (Figures $5 \mathrm{c}$ and $5 \mathrm{~d}$ ), dispersion of the bulk modulus is quite obvious from 0.004 to $1.1 \mathrm{~Hz}$. The bulk modulus increases continuously with increasing frequency. For $P_{\text {dif }}=30 \mathrm{MPa}$, the bulk modulus at $1 \mathrm{~Hz}$ almost reaches the value at $10^{6} \mathrm{~Hz}$ derived from the ultrasonic velocities. The evolution of the bulk modulus is consistent with the bell-shaped curve of the corresponding attenuation. Furthermore, the dispersion and attenuation are decreased by increasing differential pressure.

\subsection{Axial Oscillation Results}

The direct measured elastic moduli obtained by axial oscillation along with those derived from ultrasonic velocities are presented in Figure 6 as the function of apparent frequency $f^{*}=f \times \eta / \eta_{0}$, where $f$ is the testing frequency, $\eta$ is the viscosity of saturating fluid, and $\eta_{0}$ is the viscosity of water used as the reference fluid. Accounting for fluid viscosity, apparent frequency enables us to effectively broaden the frequency range.

Young's modulus $E$ (Figure 6a) and Poisson's ratio $v$ (Figure 6c) for the dry measurements increase with increasing differential pressure. In the frequency range of axial oscillations, both elastic moduli show slight

Table 2

Physical Properties of Pore Fluids

\begin{tabular}{lccc}
\hline Fluid type & $\begin{array}{c}\text { Density } \\
\left(\mathrm{kg} / \mathrm{m}^{3}\right)\end{array}$ & $\begin{array}{c}\text { Bulk modulus } \\
(\mathrm{GPa})\end{array}$ & Viscosity $\left(10^{-3} \mathrm{~Pa} \cdot \mathrm{s}\right)$ \\
\hline Air & 1.17 & $10^{-4}$ & $10^{-2}$ \\
Tap water & 1,000 & 2.25 & 1 \\
\hline
\end{tabular}

frequency dependence. The corresponding attenuation $Q_{E}^{-1}$ (Figure 6b) and $Q_{\nu}^{-1}$ (Figure 6d) are close to 0 .

For the water-saturated sample, both Young's modulus $E$ (Figure 6a) and Poisson's ratio $v$ (Figure $6 \mathrm{c}$ ) increase with increasing frequency for most of the differential pressures, although $v$ shows some fluctuation and seems to slightly decrease with frequency for differential pressures at 10 and 

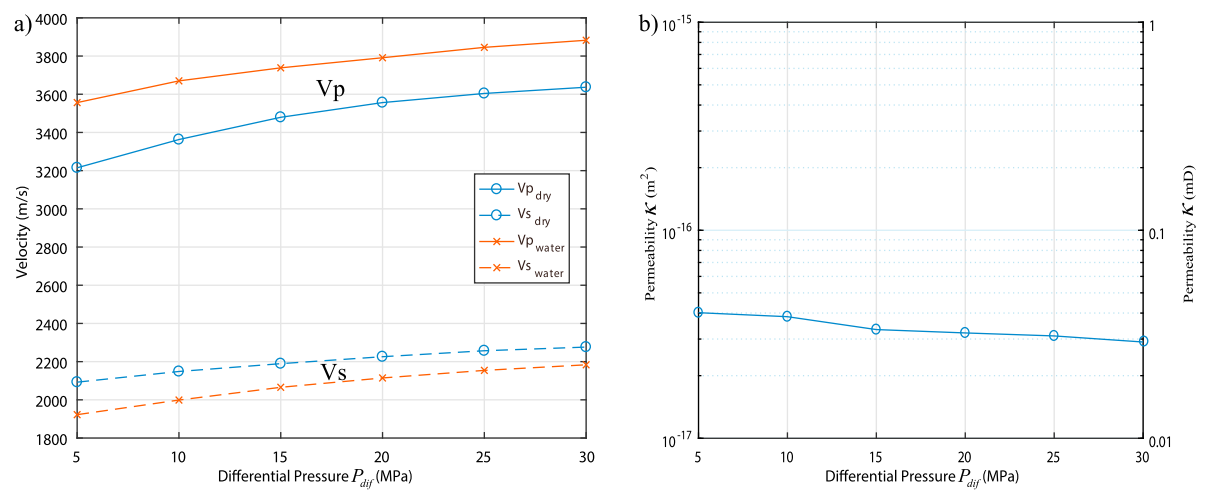

Figure 4. (a) Ultrasonic velocities and (b) permeability changing with differential pressure.

$15 \mathrm{MPa}$. There is some frequency dependence of the corresponding attenuation in Figures $6 \mathrm{~b}$ and $6 \mathrm{~d}$, and the peaks of attenuation can be seen around $0.1 \mathrm{~Hz}$ in agreement with the results obtained on the attenuation of bulk modulus $Q_{K}^{-1}$ in Figure 5d. Furthermore, the attenuations $Q_{E}^{-1}$ (Figure 6b) and $Q_{\nu}^{-1}$ (Figure 6d) are decreased by increasing differential pressure.

The measurements reveals sharp transitions of $E$ (Figure 6a) and $\nu$ (Figure $6 \mathrm{c}$ ) when changing from dry to water saturation conditions. For any given differential pressure, $E$ decreases by about 5 GPa, while $\nu$ increases by close to 0.2 .

\subsection{Uncertainty Analysis}

To assess the uncertainty for hydrostatic oscillation, we follow Borgomano et al.'s (2017) procedure using statistical analysis of a set of measurements. For bulk modulus $K_{\text {hydro }}$ with uncertainty $u\left(K_{\text {hydro }}\right)$, the relative uncertainty is $u\left(K_{\text {hydro }}\right) / K_{\text {hydro }}$. Based on equation (2), the relative uncertainty in bulk modulus is given by
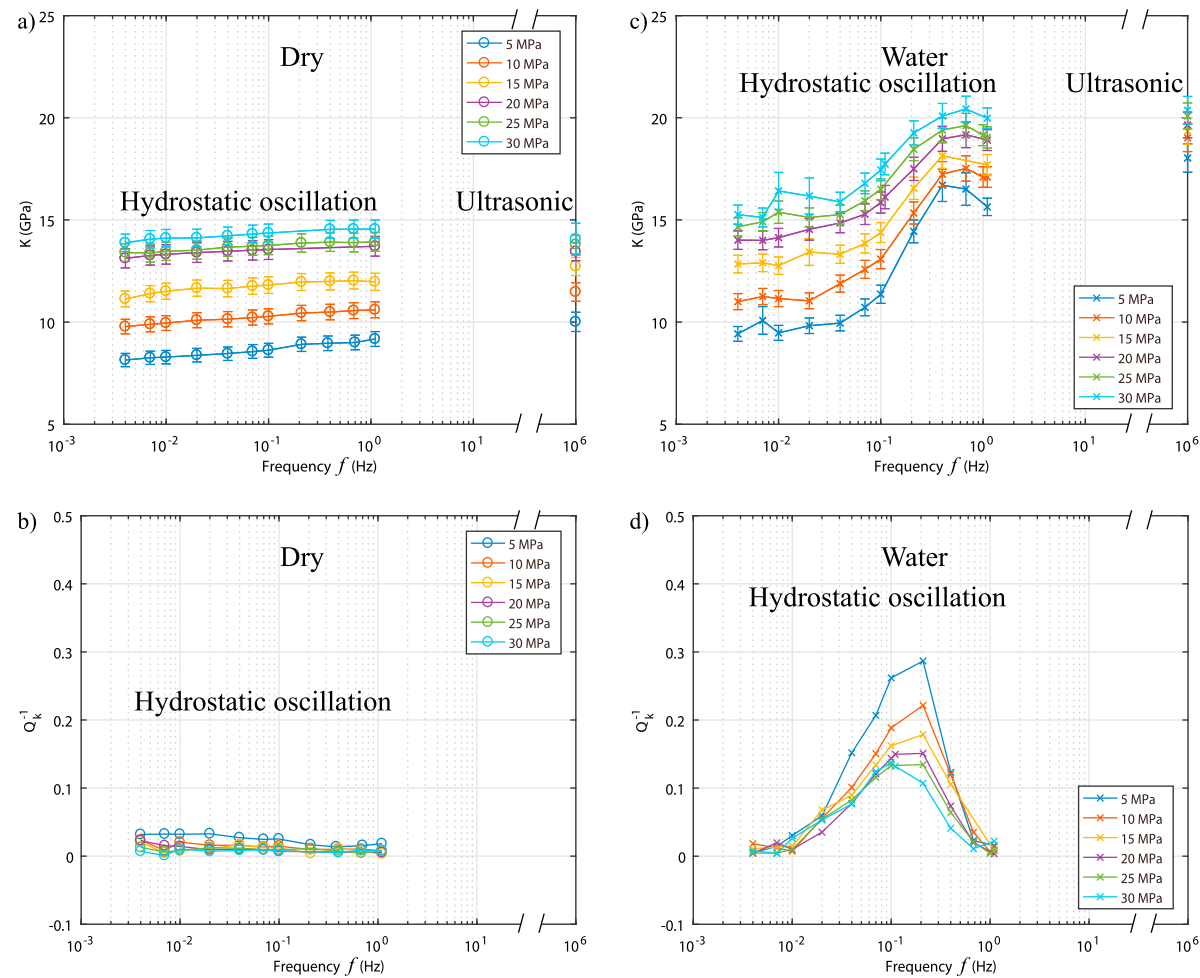

Figure 5. Bulk modulus and corresponding attenuation of hydrostatic oscillation and ultrasonic results for the sample under ( $\mathrm{a}$ and $\mathrm{b}$ ) dry and (c and d) water-saturated conditions at different differential pressures. 

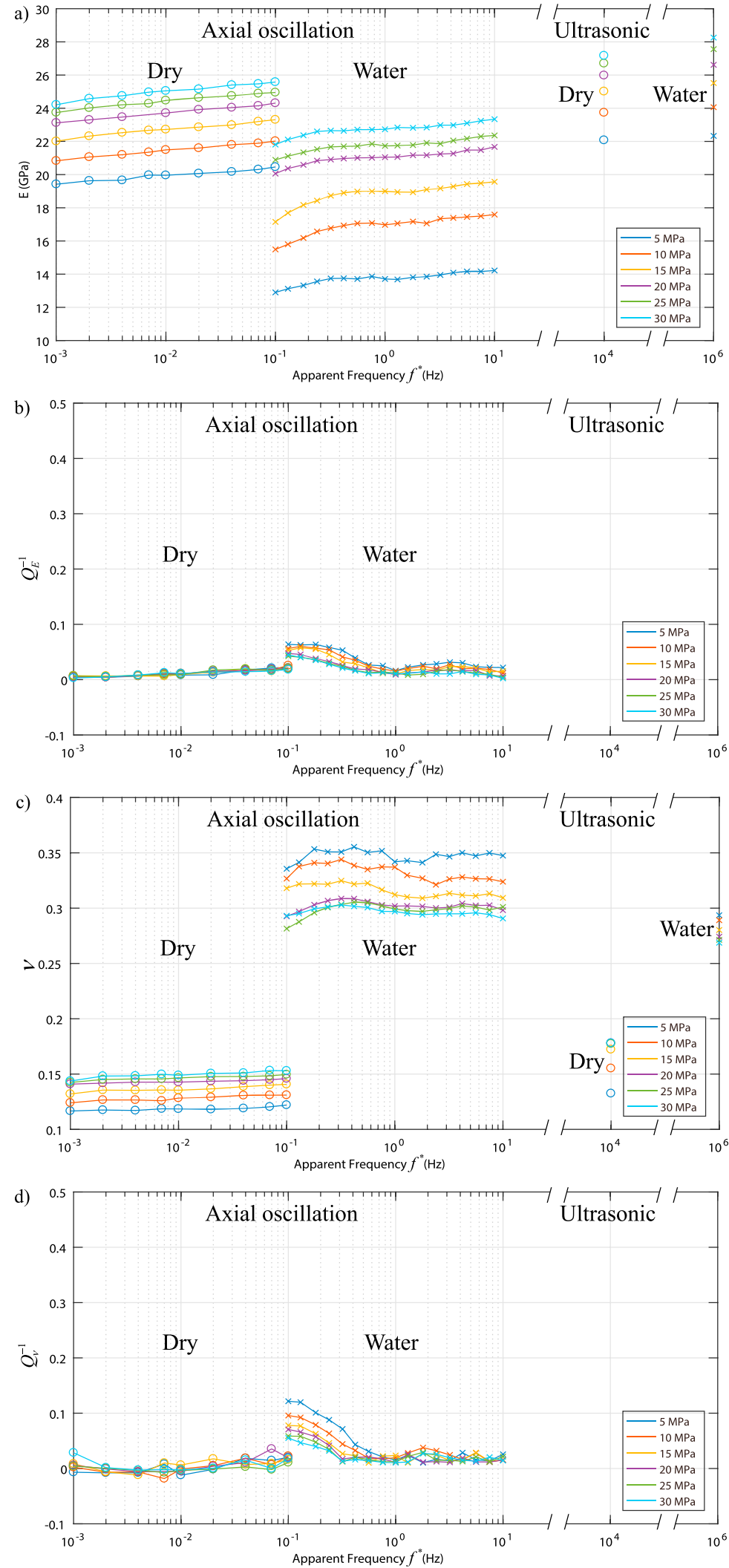

Figure 6. Axial oscillation and ultrasonic results for the sample under dry and water-saturated conditions at different differential pressures: (a) Young's modulus $E$ and (b) corresponding attenuation $Q_{E}^{-1}$, and (c) Poisson's ratio $\nu$ and (d) corresponding attenuation $Q_{\nu}^{-1}$. 


$$
\frac{u\left(K_{\text {hydro }}\right)}{K_{\text {hydro }}}=\sqrt{\left(\frac{u\left(\Delta P_{c}\right)}{\Delta P_{c}}\right)^{2}+\left(\frac{u\left(\varepsilon_{\mathrm{vol}}\right)}{\varepsilon_{\mathrm{vol}}}\right)^{2}}
$$

where $u\left(\Delta P_{c}\right)$ and $u\left(\varepsilon_{\mathrm{vol}}\right)$ are the uncertainties in the oscillating confining stress $\Delta P_{c}$ and the volumetric strain $\varepsilon_{\mathrm{vol}}$, respectively.

The resolution of the pressure sensor inside the cell for hydrostatic oscillation is $u\left(\Delta P_{c}\right)=0.001 \mathrm{MPa}$. The magnitude of the oscillating confining stress is set to be $\Delta P_{c}=0.2 \mathrm{MPa}$. Thus, the relative uncertainties in the oscillating confining stress is $u\left(\Delta P_{c}\right) / \Delta P_{c}=0.5 \%$. Eight strain gauges composed of four pairs of axial and radial strain gauges are used to obtain the volumetric strain. For the dry sample at differential pressure $P_{\text {dif }}=5 \mathrm{MPa}$ and frequency $f=0.1 \mathrm{~Hz}$, the mean of eight strains is $\varepsilon_{\mathrm{vol}}=2.36 \mu \mathrm{m} / \mathrm{m}$, and the estimated standard deviation is $s\left(\varepsilon_{\mathrm{vol}}\right)=0.258 \mu \mathrm{m} / \mathrm{m}$. The standard uncertainty, $u\left(\varepsilon_{\mathrm{vol}}\right)$, of the mean of the $n=8$ readings is calculated from $u\left(\varepsilon_{\mathrm{vol}}\right)=s\left(\varepsilon_{\mathrm{vol}}\right) / \sqrt{n}=0.091 \mu \mathrm{m} / \mathrm{m}$. This gives a relative uncertainty in the strain $u\left(\varepsilon_{\mathrm{vol}}\right) /$ $\varepsilon_{\mathrm{vol}}=3.9 \%$. Finally, the standard uncertainty in bulk modulus for hydrostatic oscillation can be derived from equation (7) and is equal to $3.9 \%$, which corresponds to the standard deviation in bulk modulus $s\left(K_{\text {hydro }}\right)=0.33 \mathrm{GPa}$. The relative uncertainties in bulk modulus for other differential pressures and frequencies have close magnitude.

Following a similar routine, the relative uncertainties in Young's modulus $u(E) / E$ and Poisson's ratio $u(\nu) / \nu$ for axial oscillation are given by

$$
\begin{aligned}
& \frac{u(E)}{E}=\sqrt{\left(\frac{u\left(\varepsilon_{a l}\right)}{\varepsilon_{a l}}\right)^{2}+\left(\frac{u\left(\varepsilon_{\text {axial }}\right)}{\varepsilon_{\text {axial }}}\right)^{2}} \\
& \frac{u(\nu)}{\nu}=\sqrt{\left(\frac{u\left(\varepsilon_{\text {axial }}\right)}{\varepsilon_{\text {axial }}}\right)^{2}+\left(\frac{u\left(\varepsilon_{\text {radial }}\right)}{\varepsilon_{\text {radial }}}\right)^{2}},
\end{aligned}
$$

where three different strains, $\varepsilon_{a l}, \varepsilon_{\text {axial }}$, and $\varepsilon_{\text {radial }}$, are each determined by four strain gauges. The relative uncertainties $u(E) / E$ and $u(\nu) / \nu$ are found to be $9.5 \%$ and $5.8 \%$, respectively. The resulting standard deviation in Young's modulus $s(E)$ and Poisson's ratio $s(\nu)$ are $s(E)=1.9 \mathrm{GPa}$ and $s(\nu)=0.006$, respectively. Propagating these uncertainties in the calculation gives the standard deviation in Bulk modulus $s(K)=1.6 \mathrm{GPa}$ and Shear modulus $s(G)=0.8 \mathrm{GPa}$.

Comparison of the uncertainty analysis from hydrostatic and axial oscillation shows that the uncertainties depend on the number of strain gauges. The more strain gauges we use, the better the estimate will be.

\section{Discussion}

\subsection{Ultrasonic Measurements}

The nonlinear variation of ultrasonic compressional and shear velocities is mainly related to the closure of microcracks (Fortin et al., 2005; Guéguen \& Boutéca, 2004; Walsh, 1965). In response to increasing differential pressure, the microcracks with various aspect ratios may gradually close. Fluid injection causes an increase in the stiffness of rock. Hence, the compressional velocity under water saturation is higher than that at dry state. In addition, the deduced shear moduli based on equation (6) are shown in Figure 7. The decrease of shear modulus after water saturation is quite obvious. Note that the difference between shear moduli under dry and water-saturated conditions decreases slightly with increasing differential pressure. In the following sections, this shear weakening effect will be discussed in detail in conjunction with the data of oscillation measurements at low frequencies.

\subsection{Hydrostatic Oscillation Measurements}

Dispersion refers to the variation of wave propagation with frequency. It is often accompanied by the decay of wave amplitude with distance, namely, attenuation. The quantitative relationship between the dispersion and corresponding attenuation satisfies the causality principle expressed by the Kramers-Kronig relationship (Mikhaltsevitch et al., 2016b; O'Donnell et al., 1981). Dispersion and attenuation for fluid-saturated rocks arise from wave-induced fluid flow in pores at different length scales (Biot, 1956a, 1956b; Gurevich et al., 2010; Johnson, 2001; Müller et al., 2010; Pride et al., 2004; White, 1975). For samples under full saturation, 


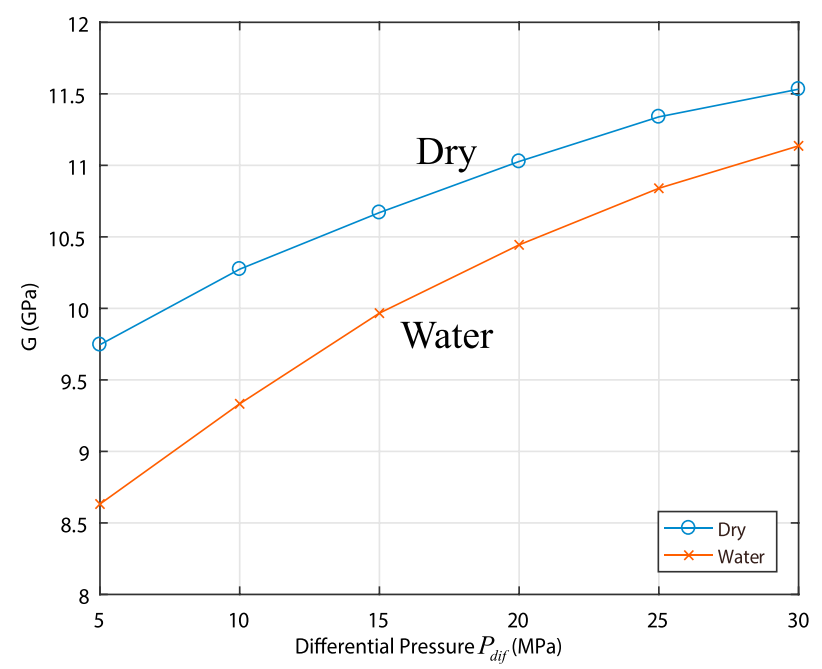

Figure 7. Shear modulus under dry and water-saturated conditions derived from ultrasonic shear velocities and corresponding density. two transitions with regard to three independent elastic regimes may be observed within a broad frequency band, which are drained/undrained transition for fluid diffusion and undrained/unrelaxed transition for squirt flow. Two apparent critical frequencies corresponding to the two transitions are found to be (Cleary, 1978; O'Connell \& Budiansky, 1977)

$$
f_{1}^{*}=\frac{4 \kappa K_{d}}{\eta_{0} L^{2}} \text { and } f_{2}^{*}=\frac{\xi_{c}{ }^{3} K_{m}}{\eta_{0}},
$$

where $L$ is the sample's length and $\xi_{c}$ is the critical crack aspect ratio. Although the estimated apparent critical frequency is approximate, it can generally represent the frequency at which the dispersion and attenuation are maximum.

At differential pressure $P_{\text {dif }}=5 \mathrm{MPa}, K_{d}$ is $8.6 \mathrm{GPa}$ for the dry sample (Figure 5a) and permeability $\kappa$ is $0.04 \times 10^{-15} \mathrm{~m}^{2}$ (Figure 4b). The sample's length is $L=0.0804 \mathrm{~m}$, and the reference fluid viscosity is $\eta_{0}=10^{-3} \mathrm{~Pa} \cdot \mathrm{s}$. This leads to a critical frequency $f_{1}^{*} \approx 0.2 \mathrm{~Hz}$ from equation (9). The predicted $f_{1}^{*}$ agrees with the measured critical frequency shown in Figure 5. Thus, it is reasonable to conclude that the drained/undrained transition is observed for critical frequency $f_{1}^{*} \approx 0.2 \mathrm{~Hz}$. In addition, the critical crack aspect ratio $\xi_{c}$ for the squirt flow can be approximately determined by $\xi_{c} \approx P_{\text {close }} / E_{m}=3.4 \times 10^{-4}$, where $P_{\text {close }}$ is the closure pressure for cracks and $E_{m}$ is the Young's modulus for the mixed mineral matrix (Walsh, 1965). Thus, the critical frequency $f_{2}^{*}$ for the relaxation of local pore pressure gradients is about $1.3 \mathrm{kHz}$. However, there are no data in the apparent frequency range between $10^{\circ}$ and $10^{6} \mathrm{~Hz}$. The observed difference between bulk moduli at $10^{0}$ and $10^{6} \mathrm{~Hz}$ is likely to be related to a transition from undrained to unrelaxed regimes.

For drained/undrained transition, a 1-D poroelastic model is proposed by solving the diffusion equation for the perturbation in pore pressure $P_{f}(z, t)$ along the $z$ axis at any time $t$ (Pimienta, Borgomano, et al., 2016),

$$
\frac{\partial P_{f}}{\partial t}-\frac{\kappa}{\eta S_{S}} \frac{\partial^{2} P_{f}}{\partial z^{2}}=B \frac{\partial P_{c}}{\partial t}
$$

where $\kappa$ is the permeability and $\eta$ is the fluid viscosity. $S_{s}=\alpha /\left(B K_{d}\right)$ is the rock storage coefficient, which depends on the bulk modulus $K_{d}$, Biot's coefficient $\alpha$, and Skempton's coefficient $B . \alpha$ and $B$ are two poroelastic coefficients associated with rock's intrinsic elastic moduli and can be expressed as $\alpha=\left(K_{m}-K_{d}\right) / K_{m}$ and $B=\left(K_{u}-K_{d}\right) /\left(\alpha K_{u}\right)$ (Detournay \& Cheng, 2014).

The specific solution for the experimentally undrained boundary condition with a constant dead volume can be calculated:

$$
P_{f}(z, t)=B \Delta P_{c} e^{\mathrm{i} \omega \mathrm{t}}\left\{1-\frac{\cosh \left[a\left(\frac{L}{2}-z\right)\right]}{b \sinh \left(a \frac{L}{2}\right)+\cosh \left(a \frac{L}{2}\right)}\right\},
$$

with $a=(1+i) \sqrt{\omega / 2 D}$ and $b=(1-i) A S_{S} \sqrt{2 D /\left(\omega S^{2}\right)}$, where $D=\kappa /\left(\eta S_{S}\right)$ is the fluid hydraulic diffusivity. $A$ is the cross-sectional area of the sample. $S$ is the storage capacity of the dead volume, given by $S=V_{\text {dead }} / K_{f}$, where $V_{\text {dead }}$ is the dead volume. The global average pore pressure can be easily calculated by integrating the local pore pressure $P_{f}(z, t)$ along the length $L$ of the sample, given by $\frac{1}{L} \int_{0}^{L} P_{f}(z, t) \mathrm{d} z$.

With the known confining and pore pressures, the local volumetric strain $\varepsilon_{\mathrm{vol}}$ is defined by $\varepsilon_{\mathrm{vol}}(z, t)=K_{d}^{-1}$ $\left[P_{c}(t)-\alpha P_{f}(z, t)\right]$. Thus, the local bulk modulus and corresponding attenuation can be calculated,

$$
\begin{aligned}
& K_{\text {model }}(z)=-\left|P_{c}(t)\right| /\left|\varepsilon_{\mathrm{vol}}(z, t)\right|, \\
& Q_{K_{\text {model }}}^{-1}(z)=\tan \left(\varphi_{1}-\varphi_{2}\right)
\end{aligned}
$$

where the amplitude $\left(\left|P_{c}(t)\right|\right)$ and phase angles $\left(\varphi_{1}\right.$ and $\left.\varphi_{2}\right)$ are extracted from the confining and pore pressures based on fast Fourier transform. Similarly, the global elastic moduli can also be obtained by using 


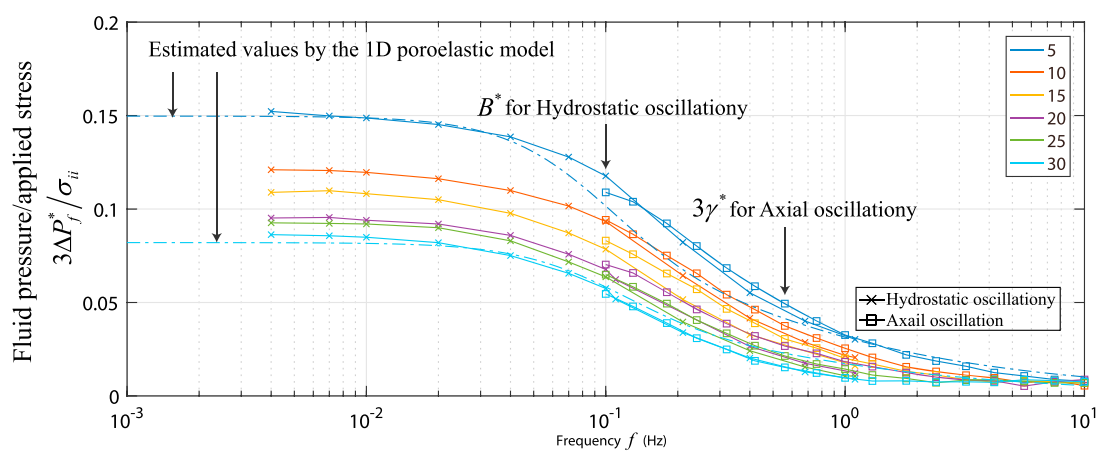

Figure 8. Comparison between predicted and measured ratio fluid pressure over applied stress. Pseudo-Skempton's coefficient $B^{*}$ for hydrostatic oscillation (solid line with cross markers) and pseudoconsolidation coefficient $3 \gamma^{*}$ for axial oscillation (solid line with square markers) are measured under water saturation at different differential pressures. The estimated ratio by the 1-D poroelastic model is plotted in dash-dotted line.

the global average pore pressure. Furthermore, assuming that the measured fluid pressure in the fluid pipeline is equal to the value at the sample end, then the pseudo-Skempton's coefficient $B^{*}$ can be estimated by setting $z=0$, given by $B_{\text {model }}^{*}=P_{f}(0, t) / P_{c}(t)$. It should be noted that when dead volume is very large, that is, $V_{\text {dead }}$ approaches infinity, the solution of equation (11) is reduced to the results calculated at the drained boundary condition. Whereas if dead volume reduces to 0 for the undrained condition, pore pressure is found to be independent of frequency and position, which is given by $P_{f}(t)=B P_{c}(t)$.

The ratio of the induced fluid pressure to the change in applied stress is called the pseudo-Skempton's coefficient $B^{*}$ for hydrostatic oscillation or the pseudoconsolidation coefficient $\gamma^{*}$ for axial oscillation. As shown in Figure $8, B^{*}$ agrees well with $3 \gamma^{*}$ for each differential pressure. This consistency for the two oscillation methods suggests the validity and reliability of the experimental data. The ratio $\left(B^{*}\right.$ or $\left.\gamma^{*}\right)$ is defined following the example of the definition of Skempton's coefficient $B$ and still expresses the change of pore pressure by the exerted stress on the rock sample. The only difference is the value of dead volume. In Figure 8, the comparison between the estimated and measured ratios fits considerably well for both hydrostatic and axial oscillation. The higher value of the ratio in the low-frequency range around $0.01 \mathrm{~Hz}$ indicates the stronger induced pore pressure and the more fluid flux at the boundaries of the sample. If dead volume is unlimited and equilibration time is long enough, the pore pressure gradients will be 0 even though fluid flow exists. Thus, the exerted stress will be fully distributed on the skeleton of the sample, just like the case at the pure drained condition. But with a limited dead volume in the experimentally undrained condition, the pore pressure gradient cannot fully equilibrate so that the fluid has to partially undertake some of the exerted stress, which may result in the enhancement of the stiffness of the sample. As frequency increases, the ratio gradually decreases until close to 0 in the high-frequency range around $10 \mathrm{~Hz}$. The result indicates that little or even no fluid flows out of the sample, so the sample is now at a pure undrained condition. The change of the ratio as a function of frequency in Figure 8 is a typical drained/undrained transition. In addition, the ratio in Figure 8 is suppressed by the increasing differential pressure. The sample becomes hard to compress as most of the microcracks close with differential pressure increase. Thus, less fluid flows out of the sample for higher differential pressure, leading to a small value of the ratio.

The estimated bulk modulus $K_{\text {model }}$ and corresponding attenuation $Q_{K_{\text {model }}}^{-1}$ at $P_{\text {dif }}=5$ and $30 \mathrm{MPa}$ for the local solution at the center of the sample and the global solution average over the sample's length are plotted in Figure 9 as the function of apparent frequency $f^{*}$. The local (dash-dotted line) and global (dashed line) estimated results converge at both the low- and high-frequency limit but diverge in the drained/undrained transition range. The model generally fits with the measured data confirming that the transition is caused by the global flow from the drained to the undrained condition.

At the lowest frequency, due to the limited dead volume in the experiment, the bulk modulus for the water saturation case is higher than the measured dry (drained) bulk modulus $K_{d}$. This is well predicted by the model. As frequency increases, the trend of dispersion is just somewhere in between the local and global estimations. This can be attributed to the simplicity of the 1-D model and the extreme approximation of the 

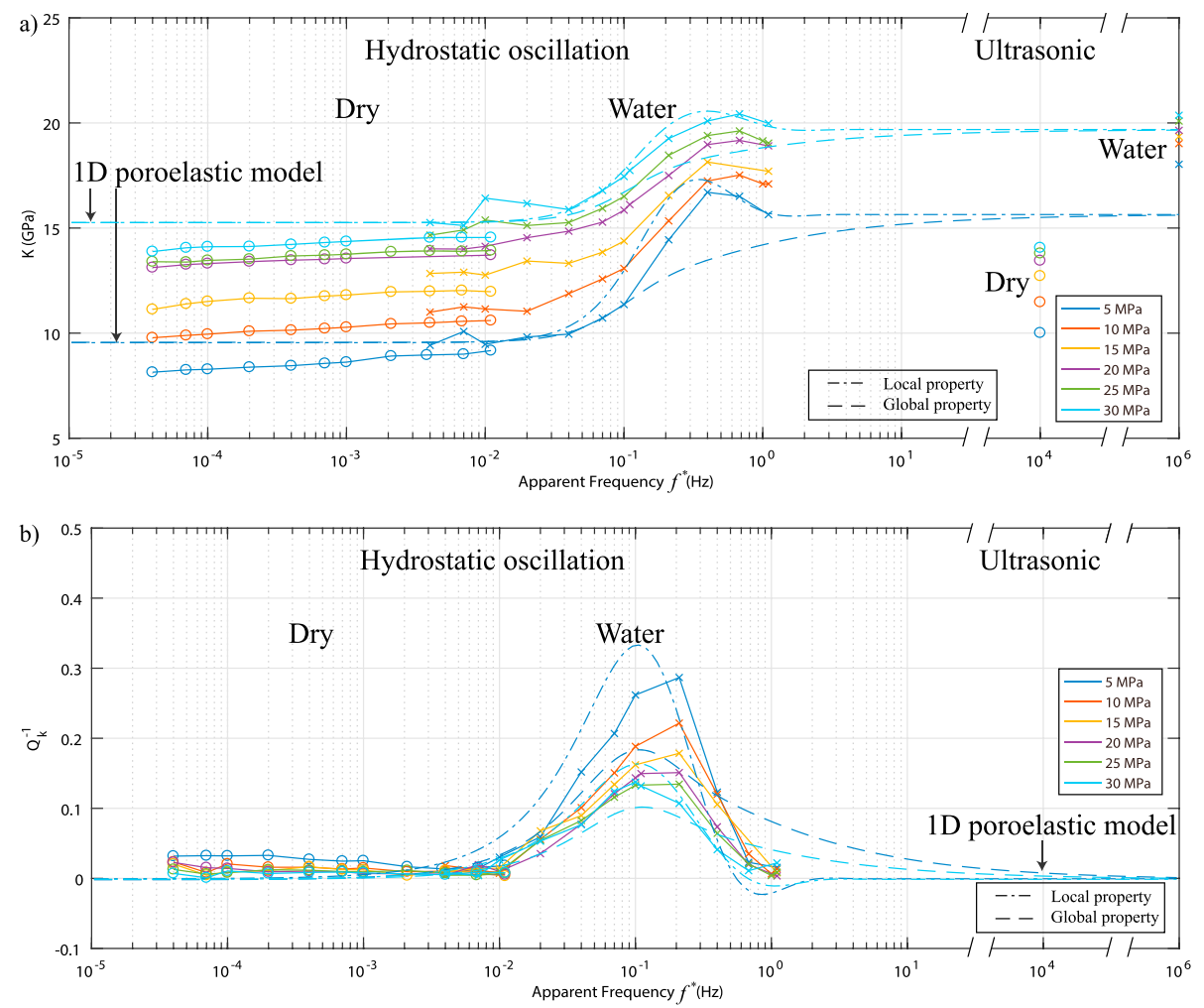

Figure 9. Comparison between the measured data and the local (dash-dotted line) and global (dashed line) estimated results by the 1-D poroelastic model for (a) the bulk modulus and (b) corresponding attenuation.

strain gauge length as a central point or the sample's length. Furthermore, it should be noted that $K_{\text {model }}$ at the highest frequency is not affected by dead volume and is always consistent with the undrained bulk modulus $K_{u}$ calculated by Gassmann's equations. A satisfactory agreement between the estimated and measured bulk moduli is observed in Figure 9 around $10^{\circ} \mathrm{Hz}$. Finally, the value of the bulk modulus $K_{\text {high }}$ derived from the ultrasonic velocities at $f=10^{6} \mathrm{~Hz}$ is still higher than the value of the bulk modulus at $f=1 \mathrm{~Hz}$. This difference is likely to result from squirt flow.

As for the attenuation, the bell-shaped curve of the estimated attenuation $Q_{K_{\text {model }}}^{-1}$ is consistent with the measured data. The estimated critical frequency $f_{1 *}$ agrees well with the frequency corresponding to the peak of the measured attenuation, which is $\sim 0.1 \mathrm{~Hz}$.

\subsection{Axial Oscillation Measurements}

Figure 10 shows the derived elastic moduli and corresponding attenuation based on axial oscillation and ultrasonic results. If the sample is purely homogeneous and isotropic, bulk modulus and attenuation measured by the two oscillation methods should be the same. We observe that the general trends of bulk modulus deduced from hydrostatic oscillation (Figure 9a) and axial oscillation (Figure 10a) with apparent frequency and differential pressure are similar. However, the hydrostatic measurements show higher bulk moduli than the axial measurements at higher differential pressures. The possible reason for this discrepancy may be the heterogeneity and anisotropy of the sample. In addition, more importantly, highly consistent results are obtained for the attenuation of bulk modulus from the two oscillation methods. That means that the dispersion and attenuation for the axial oscillation are also due to the drained/undrained transition, which is the same as for the hydrostatic oscillation.

As Gassmann's theory can be successfully used to estimate the undrained bulk modulus for this rock under water saturation, we expect the shear modulus to remain constant after fluid substitution as predicted by Gassmann's theory. However, the comparison of shear moduli under dry and water-saturated conditions in Figure 10c shows a clear shear weakening. For each condition, the shear modulus shows almost no 

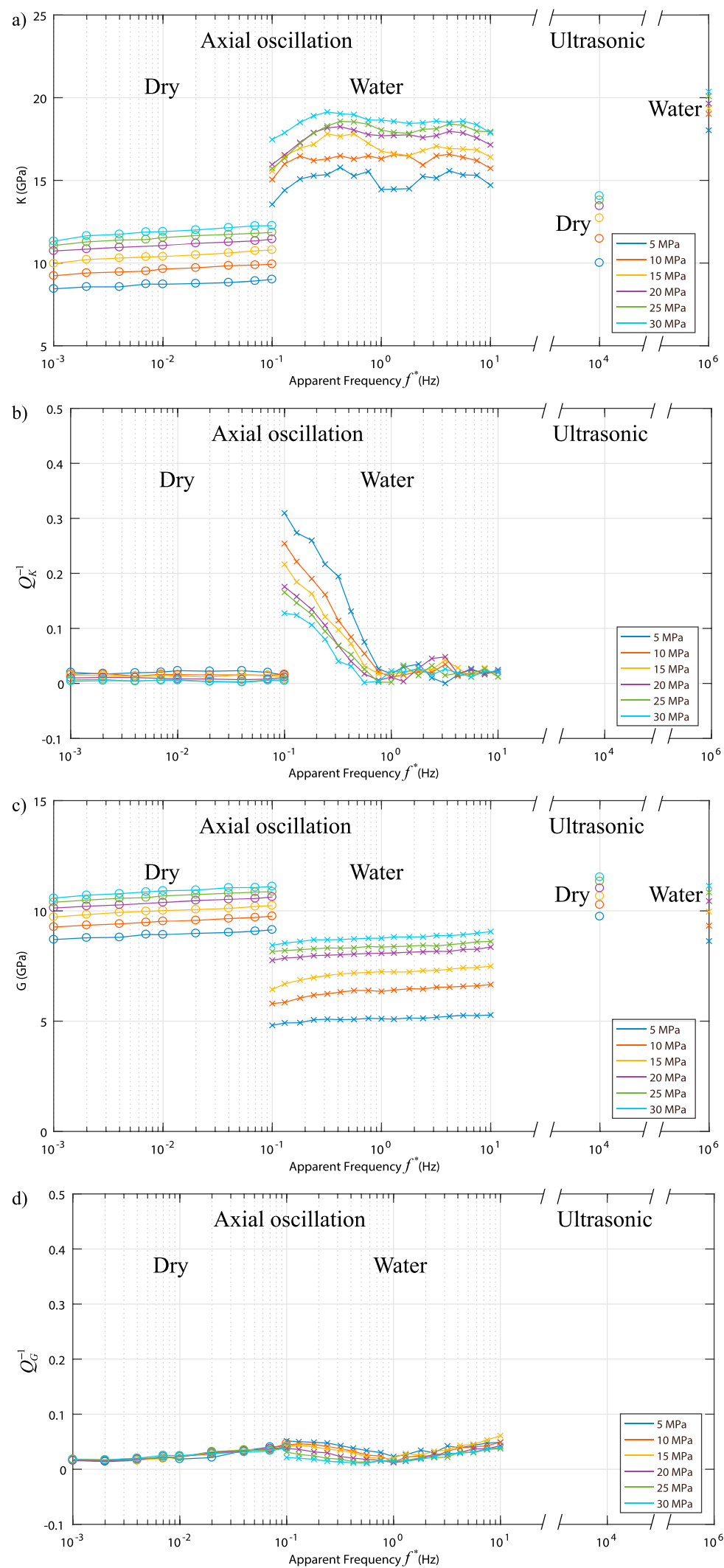

Figure 10. The derived elastic moduli and corresponding attenuation of the sample under dry and water-saturated conditions as a function of apparent frequency for axial oscillation and ultrasonic results: (a) bulk modulus $K$ and (b) corresponding attenuation $Q_{K}^{-1}$, and (c) shear modulus $G$ and (d) corresponding attenuation $Q_{G}^{-1}$. 


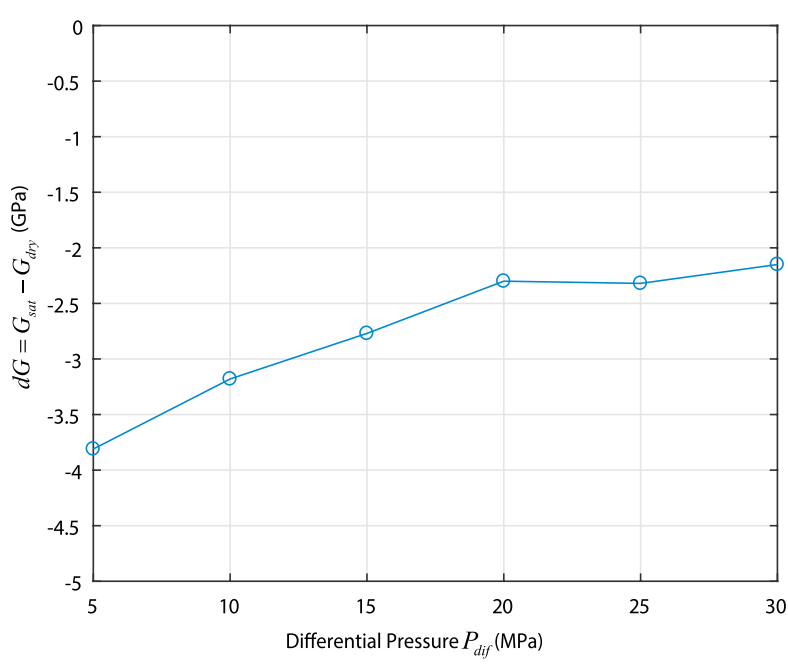

Figure 11. The difference between the dry and water-saturated shear moduli at $1 \mathrm{~Hz}$ as a function of differential pressure for the Thüringen sandstone. frequency dependence within the uncertainty of our measurements, which is consistent with the corresponding attenuation. That is to say, the shear weakening does not lead to any dissipation.

\subsection{Shear Weakening Effect}

Previous studies have shown that a reduction in shear modulus may arise from two main mechanisms: surface free energy variation related to chemical reaction between fluid and solid phases (Clark et al., 1980; Khazanehdari \& Sothcott, 2003; Murphy et al., 1984, 1986; Pimienta et al., 2014) and mechanical changes of rock skeleton and pore structure due to pressurized pore pressure (Christensen \& Wang, 1985; Paterson \& Wong, 2005).

Work by Johnson et al. (1971), Michalske and Freiman (1983), and Sedlmeier et al. (2008) illustrates that water as a polar fluid can effectively weaken rocks. Compared with nonpolar fluid, surface energy may be largely reduced in contact with water. Water molecules can bond to the solid surface of minerals, so part of the solid-solid bonds will be replaced by the hydrogen bonding network, thereby reducing the activation energy and lowering the cohesion of grain contacts (Michalske \& Freiman, 1983).

The grain contact adhesion hysteresis model provided by Tutuncu and Sharma (1992) and Bui and Tutuncu (2015) shows that Hamaker constant has a large influence on the fluid-rock interaction and deformation. The reduction of Hamaker constant due to water saturation will decrease the attractive forces acting on the surface and thus increase the equilibrium separation distance between particles and decrease the surface energy (Tutuncu, Podio, Gregory, \& Sharma, 1998; Tutuncu, Podio, \& Sharma, 1998).

Khazanehdari and Sothcott (2003) emphasized that surface energy is strongly dependent on pore surface area. Figure 11 shows the difference of saturated shear modulus and dry shear modulus $d G=G_{\text {sat }}-G_{\text {dry }}$ at the measured frequency of $1 \mathrm{~Hz}$. The sample at lowest differential pressure has the strongest shear weakening around $4 \mathrm{GPa}$. This nonlinear change of $d G$ with differential pressure can also be explained by the closure of microcracks as the variation of velocities with pressure. The increasing differential pressure starts to close the pores with small aspect ratio and thus decreases the surface area of rock in contact with water and increase the grain compaction. The corresponding increase of the surface energy will eventually decrease the weakening effect.

The shear modulus of the saturated sample is reduced by $42.7 \%$ with respect to that of the dry sample at the lowest differential pressure. The effect of fluid-solid interaction on shear weakening is relatively high in contrast with former ultrasonic studies (Han et al., 1986; Khazanehdari \& Sothcott, 2003). As far as we know, only the results of low-frequency measurements on carbonate samples by Adams et al. (2006) have shown such a large amount of softening of shear modulus. The common ground between these two experiments noticing a large shear weakening is that the measurements are conducted in the seismic frequency range. Although dispersion can in some cases mask the real shear weakening at ultrasonic frequencies, the saturated shear modulus at seismic frequencies in our study is not influenced by the stiffening effect related to dispersion. That is why the shear weakening is more obvious for the measurements in the lowfrequency range.

Furthermore, considering a high fraction of clay for the water-saturated Thüringen sample, it is reasonable to assume that clay minerals have a strong effect on the overall rock response for shear behavior. The layers in clay minerals are composed of two basic units: tetrahedral silicate sheet $(\mathrm{T})$ and octahedral hydroxide sheet $(\mathrm{O})$. Depending on the formation of mineral sheets packaged into the layer, the positive exchangeable interlayer cations may be needed to achieve charge balance between layers. Thus, the layered structural clay is formed from a pile of layers interspaced with the soft interlayers. Sayers and den Boer (2016) studied the elastic anisotropy of clay minerals and illustrated that the shear modulus for clay minerals can have considerably small value. The porous clay minerals, especially chlorite-smectite and illite-smectite, provide a large surface area of pore network available for efficient fluid-clay interaction. Ultrasonic measurements in sandstones reported by Tosaya (1982) and Han et al. (1986) suggest that shear modulus of clay minerals can be 
significantly reduced by water adsorption. The absorption of water will form one, two, or three layers of interlayer water molecules depending on the type of clay. The corresponding basal layer spacing (the spacing of a layer and an interlayer) will thus increase causing the reduction in shear modulus of clay minerals from the dry state (Sayers \& den Boer, 2016). Then, the overall shear modulus of the rock would show this softening.

To determine the amount of reduction in shear modulus of the mixed clay minerals due to water softening, we use a simple model by combining the Reuss model and the effective media model to estimate the shear moduli of the mixed clay minerals under dry and water-saturated states.

From the field emission scanning electron microscopy images in Figure 3, the main grain minerals (quartz and feldspar) are coated with different clay minerals. Thus, we assume that the bulk modulus $K_{m}$ and shear modulus $G_{m}$ of the mixed mineral matrix can be estimated from the Reuss average (Reuss, 1929),

$$
\begin{aligned}
& \frac{1}{K_{m}}=\frac{x_{\text {quartz }}}{K_{\text {quartz }}}+\frac{x_{\text {feldspar }}}{K_{\text {feldspar }}}+\frac{x_{\text {clay }}}{K_{\text {clay }}} \\
& \frac{1}{G_{m}}=\frac{x_{\text {quartz }}}{G_{\text {quartz }}}+\frac{x_{\text {feldspar }}}{G_{\text {feldspar }}}+\frac{x_{\text {clay }}}{G_{\text {clay }}},
\end{aligned}
$$

where $x_{\text {quartz }}, x_{\text {feldspar}}$, and $x_{\text {clay }}$ are the volume fractions of quartz, feldspar, and mixed clay minerals, respectively. These values are presented in Table 1 . The quartz properties are $K_{\text {quartz }}=37 \mathrm{GPa}$ and $G_{\text {quartz }}=44 \mathrm{GPa}$. The feldspar properties are $K_{\text {feldspar }}=37.5 \mathrm{GPa}$ and $G_{\text {feldspar }}=15 \mathrm{GPa}$. Since the sample's bulk modulus at the pore pressure equilibration state remains unchanged after water saturation in Figure 9a, we further assume that the constant bulk modulus of the clay minerals is $K_{\text {clay }}=25 \mathrm{GPa}$ based on the laboratory measurements by Castagna et al. (1985) and Han et al. (1986). Thus, the only unknown is the shear modulus $G_{\text {clay }}$ of the mixed clay minerals.

Under the pore pressure equilibrium case, the effective shear modulus $G_{\text {eff }}$ for an effective medium with only equant pores is given by (Mavko et al., 2009)

$$
\frac{G_{m}}{G_{\text {eff }}}=1+\phi \frac{15\left(1-v_{m}\right)}{7-5 v_{m}}
$$

where $\nu_{m}=\frac{3 K_{m}-2 G_{m}}{2\left(3 K_{m}+G_{m}\right)}$ is the Poisson's ratio of the mixed mineral matrix. In fact, $G_{\text {eff }}$ is a function of $K_{m}$ and $G_{m}$ through $\nu_{m}$. It can be taken as the shear modulus of the sample at the highest differential pressure $30 \mathrm{MPa}$, where all the microcracks are assumed to be closed. Under the seismic frequency range where pore pressure reaches equilibration in Figure 10c, $G_{\text {eff }}$ decreases from $10.9 \mathrm{GPa}$ under dry state to $8.8 \mathrm{GPa}$ under water saturation. Then $G_{\text {clay }}$ can be obtained by solving the simultaneous equations, which combine equations (13) and (14). Thus, the values are found to be $G_{\text {clay_dry }}=4.49 \mathrm{GPa}$ under dry condition and $G_{\text {clay_water }}=3.2 \mathrm{GPa}$ under water condition. The shear modulus of mixed clay minerals decreased by $28.7 \%$ due to water softening effect.

Finally, the damage of grain cement and contacts by the pressurized pore fluid may not be the reason for the observed shear weakening because pore pressure is only $3 \mathrm{MPa}$ for all the measurements. Thus, the weakening effect in this water-saturated sample is believed to be mainly caused by the reduction of surface free energy due to fluid-solid interaction.

\section{Conclusion}

The experimental measurements on a clay-bearing Thüringen sandstone were conducted to better understand Gassmann's theory for fluid substitution. The elastic properties of the sample under dry and water saturation were measured in a broad frequency range by the forced oscillation method combined with the ultrasonic transmission method.

The elastic moduli of the dry sample show no frequency dependence. However, the dispersion and attenuation can be clearly observed for the water-saturated sample, which confirms that the underlying mechanism for the frequency dependence of elastic moduli is mainly due to the fluid inside the pore space of the sample. 
For the sample under water saturation, the measured bulk modulus for hydrostatic oscillation increases with frequency in the seismic frequency band. The corresponding attenuation correlates well with the dispersion. The estimated data by the 1-D poroelastic model accounting for the experimental boundary conditions match well with the measured results, implying that the low-frequency dispersion and attenuation are induced by the transition from the drained to the undrained regimes. These results also indicate that the effect of limited dead volume on bulk modulus needs to be considered.

The undrained bulk modulus estimated by Gassmann's theory is consistent with the measured data. However, there is a clear shear weakening effect for axial oscillation, which violates the constant shear modulus assumption derived from Gassmann's prediction. The reduction of surface energy due to fluid-solid interaction is assumed to be the main cause for the shear weakening at seismic frequencies. The presence of many clay minerals with a large surface area is the likely cause of the shear weakening. The decrease of shear modulus at ultrasonic frequencies is smaller than that observed at seismic frequencies. This is mainly related to the stiffening effect of dispersion and very likely due to squirt flow. The application of Gassmann's theory on clay-rich reservoirs may consequently cause errors in seismic inversion, amplitudeversus-offset, or time-lapse seismic analysis.

\section{Acknowledgments}

This work is sponsored by National Science and Technology Major Project no. 2017ZX05018-005. The authors wish to thank Editor Douglas Schmitt, Associate Editor Beatriz Quintal, and three anonymous reviewers for their constructive comments. The presented data for this paper can be found in the supporting information.

\section{References}

Adam, L., Batzle, M., \& Brevik, I. (2006). Gassmann's fluid substitution and shear modulus variability in carbonates at laboratory seismic and ultrasonic frequencies. Geophysics, 71(6), F173-F183. https://doi.org/10.1190/1.2358494

Adelinet, M., Domínguez, C., Fortin, J., \& Violette, S. (2018). Seismic-refraction field experiments on Galapagos Islands: A quantitative tool for hydrogeology. Journal of Applied Geophysics, 148, 139-151. https://doi.org/10.1016/j.jappgeo.2017.10.009

Adelinet, M., Fortin, J., \& Guéguen, Y. (2011). Dispersion of elastic moduli in a porous-cracked rock: Theoretical predictions for squirtflow. Tectonophysics, 503(1-2), 173-181. https://doi.org/10.1016/j.tecto.2010.10.012

Adelinet, M., Fortin, J., Guéguen, Y., Schubnel, A., \& Geoffroy, L. (2010). Frequency and fluid effects on elastic properties of basalt: Experimental investigations. Geophysical Research Letters, 37, L02303. https://doi.org/10.1029/2009GL041660
Assefa, S., McCann, C., \& Sothcott, J. (2003). Velocities of compressional and shear waves in limestones. Geophysical Prospecting, 51(1), 1-13. https://doi.org/10.1046/j.1365-2478.2003.00349.x

Avseth, P., Mukerji, T., \& Mavko, G. (2010). Quantitative seismic interpretation: Applying rock physics tools to reduce interpretation risk. New York: Cambridge University Press.

Baechle, G. T., Eberli, G. P., Weger, R. J., \& Massaferro, J. L. (2009). Changes in dynamic shear moduli of carbonate rocks with fluid substitution. Geophysics, 74(3), E135-E147. https://doi.org/10.1190/1.3111063

Batzle, M. L., Han, D., \& Hofmann, R. (2006). Fluid mobility and frequency-dependent seismic velocity-Direct measurements. Geophysics, 71(1), N1-N9. https://doi.org/10.1190/1.2159053

Berryman, J. G. (1999). Origin of Gassmann's equations. Geophysics, 64(5), 1627-1629. https://doi.org/10.1190/1.1444667

Best, A. I., Sothcott, J., \& McCann, C. (2007). A laboratory study of seismic velocity and attenuation anisotropy in near-surface sedimentary rocks. Geophysical Prospecting, 55(5), 609-625. https://doi.org/10.1111/j.1365-2478.2007.00642.x

Bhuiyan, M. H., \& Holt, R. M. (2016). Variation of shear and compressional wave modulus upon saturation for pure pre-compacted sands. Geophysical Journal International, 206(1), 487-500. https://doi.org/10.1093/gji/ggw156

Biot, M. A. (1956a). Theory of propagation of elastic waves in a fluid-saturated porous solid. I. Low-frequency range. The Journal of the Acoustical Society of America, 28(2), 168-178. https://doi.org/10.1121/1.1908239

Biot, M. A. (1956b). Theory of propagation of elastic waves in a fluid-saturated porous solid. II. Higher frequency range. The Journal of the Acoustical Society of America, 28(2), 179-191. https://doi.org/10.1121/1.1908241

Birch, F. (1961). The velocity of compressional waves in rocks to 10 kilobars. Part 2. Journal of Geophysical Research, 66(7), 2199-2224. https://doi.org/10.1029/JZ066i007p02199

Borgomano, J. V. M. (2018). Dispersion of elastic moduli of saturated carbonates: Experimental study and modelisation, (doctoral dissertation). Laboratory of Geology, Ecole Normale Superieure de Paris - ENS Paris; PSL Research University.

Borgomano, J. V. M., Pimienta, L., Fortin, J., \& Guéguen, Y. (2017). Dispersion and attenuation measurements of the elastic moduli of a dual-porosity limestone. Journal of Geophysical Research: Solid Earth, 122, 2690-2711. https://doi.org/10.1002/ 2016JB013816

Bui, B. T., \& Tutuncu, A. N. (2015). Effect of capillary condensation on geomechanical and acoustic properties of shale formations. Journal of Natural Gas Science and Engineering, 26, 1213-1221. https://doi.org/10.1016/j.jngse.2015.08.027

Cadoret, T. (1993). Effet de la saturation eau-gaz sur les proprietes acoustiques des roches: Etude aux frequences sonores et ultrasonores (doctoral dissertation). University of Paris VII.

Castagna, J. P., Batzle, M. L., \& Eastwood, R. L. (1985). Relationships between compressional-wave and shear-wave velocities in clastic silicate rocks. Geophysics, 50(4), 571-581. https://doi.org/10.1190/1.1441933

Christensen, N. I., \& Wang, H. F. (1985). The influence of pore pressure and confining pressure on dynamic elastic properties of Berea sandstone. Geophysics, 50(2), 207-213. https://doi.org/10.1190/1.1441910

Clark, V. A., Tittmann, B. R., \& Spencer, T. W. (1980). Effect of volatiles on attenuation $\left(\mathrm{Q}^{-1}\right)$ and velocity in sedimentary rocks. Journal of Geophysical Research, 85(B10), 5190-5198. https://doi.org/10.1029/JB085iB10p05190

Cleary, M. P. (1978). Elastic and dynamic response regimes of fluid-impregnated solids with diverse microstructures. International Journal of Solids and Structures, 14(10), 795-819. https://doi.org/10.1016/0020-7683(78)90072-0

David, E. C., Fortin, J., Schubnel, A., Guéguen, Y., \& Zimmerman, R. W. (2013). Laboratory measurements of low- and high-frequency elastic moduli in Fontainebleau sandstone. Geophysics, 78(5), D369-D379. https://doi.org/10.1190/geo2013-0070.1

Detournay, E., \& Cheng, A. H. (2014). Fundamentals of poroelasticity. Analysis and Design Methods: Comprehensive Rock Engineering: Principles, Practice and Projects, 2, 113. 
Diethart-Jauk, E., \& Gegenhuber, N. (2018). Shear weakening for different lithologies observed at different saturation stages. Journal of Applied Geophysics, 148, 107-114. https://doi.org/10.1016/j.jappgeo.2017.11.011

Domenico, S. N. (1977). Elastic properties of unconsolidated porous sand reservoirs. Geophysics, 42(7), 1339-1368. https://doi.org/10.1190/ 1.1440797

Ellis, D. V., \& Singer, J. M. (2007). Well logging for Earth scientists. Dordrecht: Springer. https://doi.org/10.1007/978-1-4020-4602-5

Fortin, J., Guéguen, Y., \& Schubnel, A. (2007). Effects of pore collapse and grain crushing on ultrasonic velocities and Vp/Vs. Journal of Geophysical Research, 112, B08207. https://doi.org/10.1029/2005JB004005

Fortin, J., Pimienta, L., Guéguen, Y., Schubnel, A., David, E. C., \& Adelinet, M. (2014). Experimental results on the combined effects of frequency and pressure on the dispersion of elastic waves in porous rocks. The Leading Edge, 33(6), 648-654. https://doi.org/10.1190/ tle33060648.1

Fortin, J., Schubnel, A., \& Guéguen, Y. (2005). Elastic wave velocities and permeability during compaction of sandstone. International Journal of Rock Mechanics, 42(7-8), 873-889. https://doi.org/10.1016/j.ijrmms.2005.05.002

Gassmann, F. (1951). Über die elastizität poröser medien. Vierteljahrsschrift der Naturforschenden Gesellschaft in Zürich, 96, 1-23.

Green, D. H., \& Wang, H. F. (1994). Shear wave velocity and attenuation from pulse-echo studies of Berea sandstone. Journal of Geophysical Research, 99(B6), 11,755-11,763. https://doi.org/10.1029/94JB00506

Guéguen, Y., \& Boutéca, M. (2004). Mechanics of fluid-saturated rocks. New York: Academic Press.

Gurevich, B., Makarynska, D., de Paula, O. B., \& Pervukhina, M. (2010). A simple model for squirt-flow dispersion and attenuation in fluidsaturated granular rocks. Geophysics, 75(6), N109-N120. https://doi.org/10.1190/1.3509782

Han, D., Nur, A., \& Morgan, D. (1986). Effects of porosity and clay content on wave velocities in sandstones. Geophysics, 51(11), 2093-2107. https://doi.org/10.1190/1.1442062

Jackson, I. (2000). Laboratory measurement of seismic wave dispersion and attenuation: Recent progress. Earth's Deep Interior: Mineral Physics and Tomography From the Atomic to the Global Scale, 265-289.

Jackson, I., \& Paterson, M. S. (1993). A high-pressure, high-temperature apparatus for studies of seismic wave dispersion and attenuation. Pure and Applied Geophysics, 141(2-4), 445-466. https://doi.org/10.1007/BF00998339

Jackson, I., Schijns, H., Schmitt, D. R., Mu, J., \& Delmenico, A. (2011). A versatile facility for laboratory studies of viscoelastic and poroelastic behaviour of rocks. Review of Scientific Instruments, 82(6), 64501. https://doi.org/10.1063/1.3592154

Japsen, P., Høier, C., Rasmussen, K. B., Fabricius, I., Mavko, G., \& Pedersen, J. M. (2002). Effect of fluid substitution on ultrasonic velocities in chalk plugs, South Arne field, North Sea. Paper presented at SEG International Exposition and 72nd Annual Meeting, Salt Lake City, Utah.

Johnson, D. L. (2001). Theory of frequency dependent acoustics in patchy-saturated porous media. The Journal of the Acoustical Society of America, 110(2), 682-694. https://doi.org/10.1121/1.1381021

Johnson, K. L., Kendall, K., \& Roberts, A. D. (1971). Surface energy and the contact of elastic solids. Proceedings of the Royal Society A 324(1558), 301-313. https://doi.org/10.1098/rspa.1971.0141

Kasahara, J., \& Hasada, Y. (2016). Time lapse approach to monitoring oil, gas, and $\mathrm{CO}_{2}$ storage by seismic methods. Amsterdam: Gulf Professional Publishing.

Khazanehdari, J., \& Sothcott, J. (2003). Variation in dynamic elastic shear modulus of sandstone upon fluid saturation and substitution. Geophysics, 68(2), 472-481. https://doi.org/10.1190/1.1567213

Lumley, D. E. (2001). Time-lapse seismic reservoir monitoring. Geophysics, 66(1), 50-53. https://doi.org/10.1190/1.1444921

Madonna, C., \& Tisato, N. (2013). A new seismic wave attenuation module to experimentally measure low-frequency attenuation in extensional mode. Geophysical Prospecting, 61(2), 302-314. https://doi.org/10.1111/1365-2478.12015

Mavko, G., Mukerji, T., \& Dvorkin, J. (2009). The rock physics handbook: Tools for seismic analysis of porous media. Cambridge, U. K: Cambridge University Press. https://doi.org/10.1017/CBO9780511626753

McCarthy, C., Takei, Y., \& Hiraga, T. (2011). Experimental study of attenuation and dispersion over a broad frequency range: 2. The universal scaling of polycrystalline materials. Journal of Geophysical Research, 116, B09207. https://doi.org/10.1029/ 2011JB008384

Michalske, T. A., \& Freiman, S. W. (1983). A molecular mechanism for stress corrosion in vitreous silica. Journal of the American Ceramic Society, 66(4), 284-288. https://doi.org/10.1111/j.1151-2916.1983.tb15715.x

Mikhaltsevitch, V., Lebedev, M., \& Gurevich, B. (2014). A laboratory study of low-frequency wave dispersion and attenuation in watersaturated sandstones. The Leading Edge, 33(6), 616-622. https://doi.org/10.1190/tle33060616.1

Mikhaltsevitch, V., Lebedev, M., \& Gurevich, B. (2016a). Laboratory measurements of the effect of fluid saturation on elastic properties of carbonates at seismic frequencies. Geophysical Prospecting, 64(4), 799-809. https://doi.org/10.1111/1365-2478.12404

Mikhaltsevitch, V., Lebedev, M., \& Gurevich, B. (2016b). Validation of the laboratory measurements at seismic frequencies using the Kramers-Kronig relationship. Geophysical Research Letters, 43, 4986-4991. https://doi.org/10.1002/2016GL069269

Müller, T. M., Gurevich, B., \& Lebedev, M. (2010). Seismic wave attenuation and dispersion resulting from wave-induced flow in porous rocks-A review. Geophysics, 75(5), A147-A164.

Murphy, W. F. (1985). Sonic and ultrasonic velocities: Theory versus experiment. Geophysical Research Letters, 12(2), 85-88. https://doi. org/10.1029/GL012i002p00085

Murphy, W. F., Winkler, K. W., \& Kleinberg, R. L. (1984). Frame modulus weakening in sandstones: The effect of adsorption on surface energy. Geophysical Research Letters, 11(9), 805-808. https://doi.org/10.1029/GL011i009p00805

Murphy, W. F., Winkler, K. W., \& Kleinberg, R. L. (1986). Acoustic relaxation in sedimentary rocks: Dependence on grain contacts and fluid saturation. Geophysics, 51(3), 757-766. https://doi.org/10.1190/1.1442128

Nakagawa, S., Kneafsey, T. J., Daley, T. M., Freifeld, B. M., \& Rees, E. V. (2013). Laboratory seismic monitoring of supercritical $\mathrm{CO}_{2}$ flooding in sandstone cores using the Split Hopkinson Resonant Bar technique with concurrent X-ray computed tomography imaging. Geophysical Prospecting, 61(2), 254-269. https://doi.org/10.1111/1365-2478.12027

O'Connell, R. J., \& Budiansky, B. (1977). Viscoelastic properties of fluid-saturated cracked solids. Journal of Geophysical Research, 82(36), 5719-5735. https://doi.org/10.1029/JB082i036p05719

O'Donnell, M., Jaynes, E. T., \& Miller, J. G. (1981). Kramers-Kronig relationship between ultrasonic attenuation and phase velocity. The Journal of the Acoustical Society of America, 69(3), 696-701. https://doi.org/10.1121/1.385566

Parsons, I. (2012). Feldspars and their reactions. New York: Springer Science \& Business Media.

Paterson, M. S., \& Wong, T. (2005). Experimental rock deformation-the brittle field. Springer Science \& Business Media.

Peselnick, L., \& Liu, H. P. (1987). 2. Laboratory measurement of internal friction in rocks and minerals at seismic frequencies. Methods in Experimental Physics, Academic Press, 24, 31-56. https://doi.org/10.1016/S0076-695X(08)60583-9 
Pimienta, L., Borgomano, J. V. M., Fortin, J., \& Guéguen, Y. (2016). Modelling the drained/undrained transition: Effect of the measuring method and the boundary conditions. Geophysical Prospecting, 64(4), 1098-1111. https://doi.org/10.1111/1365-2478.12390

Pimienta, L., Borgomano, J. V. M., Fortin, J., \& Guéguen, Y. (2017). Elastic dispersion and attenuation in fully saturated sandstones: Role of mineral content, porosity, and pressures. Journal of Geophysical Research: Solid Earth, 122, 9950-9965. https://doi.org/10.1002/2017JB014645

Pimienta, L., Fortin, J., \& Guéguen, Y. (2014). Investigation of elastic weakening in limestone and sandstone samples from moisture adsorption. Geophysical Journal International, 199(1), 335-347. https://doi.org/10.1093/gji/ggu257

Pimienta, L., Fortin, J., \& Guéguen, Y. (2015a). Bulk modulus dispersion and attenuation in sandstones. Geophysics, 80(2), D111-D127. https://doi.org/10.1190/geo2014-0335.1

Pimienta, L., Fortin, J., \& Guéguen, Y. (2015b). Experimental study of Young's modulus dispersion and attenuation in fully saturated sandstones. Geophysics, 80(5), L57-L72. https://doi.org/10.1190/geo2014-0532.1

Pimienta, L., Fortin, J., \& Guéguen, Y. (2016). Effect of fluids and frequencies on Poisson's ratio of sandstone samples. Geophysics, 81(2), D35-D47. https://doi.org/10.1190/GEO-2015-0310.1

Pride, S. R., Berryman, J. G., \& Harris, J. M. (2004). Seismic attenuation due to wave-induced flow. Journal of Geophysical Research, 109, B01201. https://doi.org/10.1029/2003JB002639

Regnet, J. B., Robion, P., David, C., Fortin, J., Brigaud, B., \& Yven, B. (2015). Acoustic and reservoir properties of microporous carbonate rocks: Implication of micrite particle size and morphology. Journal of Geophysical Research: Solid Earth, 120, 790-811. https://doi.org/ 10.1002/2014JB011313

Reuss, A. (1929). Berechnung der fließgrenze von mischkristallen auf grund der plastizitätsbedingung für einkristalle. ZAMM-Journal of Applied Mathematics and Mechanics/Zeitschrift für Angewandte Mathematik und Mechanik, 9(1), 49-58. https://doi.org/10.1002/ zamm.19290090104

Saltiel, S., Bonner, B. P., \& Ajo-Franklin, J. B. (2017). Strain-dependent partial slip on rock fractures under seismic-frequency torsion. Geophysical Research Letters, 44, 4756-4764. https://doi.org/10.1002/2017GL073108

Sayers, C. M., \& den Boer, L. D. (2016). The elastic anisotropy of clay minerals. Geophysics, 81(5), C193-C203. https://doi.org/10.1190/ geo2016-0005.1

Sedlmeier, F., Janecek, J., Sendner, C., Bocquet, L., Netz, R. R., \& Horinek, D. (2008). Water at polar and nonpolar solid walls. Biointerphases, 3(3), C23-C39.

Sheriff, R. E., \& Geldart, L. P. (1995). Exploration seismology. Cambridge university press. https://doi.org/10.1017/CBO9781139168359

Smith, T. M., Sondergeld, C. H., \& Rai, C. S. (2003). Gassmann fluid substitutions: A tutorial. Geophysics, 68(2), 430-440. https://doi.org/ $10.1190 / 1.1567211$

Spencer, J. W. (1981). Stress relaxations at low frequencies in fluid-saturated rocks: Attenuation and modulus dispersion. Journal of Geophysical Research, 86(B3), 1803-1812. https://doi.org/10.1029/JB086iB03p01803

Subramaniyan, S., Quintal, B., Tisato, N., Saenger, E. H., \& Madonna, C. (2014). An overview of laboratory apparatuses to measure seismic attenuation in reservoir rocks. Geophysical Prospecting, 62(6), 1211-1223. https://doi.org/10.1111/1365-2478.12171

Szewczyk, D., Bauer, A., \& Holt, R. M. (2016). A new laboratory apparatus for the measurement of seismic dispersion under deviatoric stress conditions. Geophysical Prospecting, 64(4), 789-798. https://doi.org/10.1111/1365-2478.12425

Takei, Y., Fujisawa, K., \& McCarthy, C. (2011). Experimental study of attenuation and dispersion over a broad frequency range: 1 . The apparatus. Journal of Geophysical Research, 116, B09204. https://doi.org/10.1029/2011JB008382

Tiennot, M. (2017). Influence des propriétés physico-mécaniques des minéraux argileux dans l'altération de la pierre monumentale (doctoral dissertation). Université Pierre et Marie Curie.

Tiennot, M., Mertz, J., \& Bourgès, A. (2017). Influence of anisotropic microcracking due to swelling on the fracture toughness of a claybearing sandstone. Rock Mechanics and Rock Engineering, 50(11), 2861-2870. https://doi.org/10.1007/s00603-017-1273-4

Tisato, N., \& Madonna, C. (2012). Attenuation at low seismic frequencies in partially saturated rocks: Measurements and description of a new apparatus. Journal of Applied Geophysics, 86, 44-53. https://doi.org/10.1016/j.jappgeo.2012.07.008

Tosaya, C. A. (1982). Acoustical properties of clay-bearing rocks (doctoral dissertation). Stanford University.

Tutuncu, A. N., Podio, A. L., Gregory, A. R., \& Sharma, M. M. (1998). Nonlinear viscoelastic behavior of sedimentary rocks. Part I: Effect of frequency and strain amplitude. Geophysics, 63(1), 184-194. https://doi.org/10.1190/1.1444311

Tutuncu, A. N., Podio, A. L., \& Sharma, M. M. (1998). Nonlinear viscoelastic behavior of sedimentary rocks. Part II: Hysteresis effects and influence of type of fluid on elastic moduli. Geophysics, 63(1), 195-203. https://doi.org/10.1190/1.1444313

Tutuncu, A. N., \& Sharma, M. M. (1992). The influence of fluids on grain contact stiffness and frame moduli in sedimentary rocks. Geophysics, 57(12), 1571-1582. https://doi.org/10.1190/1.1443225

Van Der Plas, L. (2011). The identification of detrital feldspars. Amsterdam: Elsevier.

Vialle, S., \& Vanorio, T. (2011). Laboratory measurements of elastic properties of carbonate rocks during injection of reactive $\mathrm{CO}_{2}$-saturated water. Geophysical Research Letters, 38, L01302. https://doi.org/10.1029/2010GL045606

Vo-Thanh, D. (1995). Influence of fluid chemistry on shear-wave attenuation and velocity in sedimentary rocks. Geophysical Journal International, 121(3), 737-749. https://doi.org/10.1111/j.1365-246X.1995.tb06435.x

Walsh, J. B. (1965). The effect of cracks on the compressibility of rock. Journal of Geophysical Research, 70(2), 381-389. https://doi.org/ 10.1029/JZ070i002p00381

Wang, S., Zhao, J., Li, Z., Harris, J. M., \& Quan, Y. (2012). Differential acoustic resonance spectroscopy for the acoustic measurement of small and irregular samples in the low frequency range. Journal of Geophysical Research, 117, B6203. https://doi.org/10.1029/ 2011JB008808

Wang, Z. (2000). The Gassmann equation revisited: Comparing laboratory data with Gassmann's prediction. Seismic and Acoustic Velocities in Reservoir Rocks, 3, 8-23.

Wang, Z., Hirsche, W. K., \& Sedgwick, G. (1991). Seismic monitoring of water floods?-A petrophysical study. Geophysics, 56(10), 1614-1623. https://doi.org/10.1190/1.1442972

White, J. E. (1975). Computed seismic speeds and attenuation in rocks with partial gas saturation. Geophysics, 40(2), 224-232. https://doi. org/10.1190/1.1440520

Winkler, K., Nur, A., \& Gladwin, M. (1979). Friction and seismic attenuation in rocks. Nature, 277(5697), 528-531. https://doi.org/10.1038/ 277528a0

Yin, H. J., Zhao, J. G., Tang, G. Y., Zhao, L. M., Ma, X. Y., \& Wang, S. X. (2017). Pressure and fluid effect on frequency-dependent elastic moduli in fully saturated tight sandstone. Journal of Geophysical Research: Solid Earth, 122, 8925-8942. https://doi.org/10.1002/ 2017JB014244 